\title{
Carbon Cloth-based Hybrid Materials as Flexible Electrochemical Supercapacitors
}

Amit Mishra, ${ }^{[a]}$ Nagaraj P. Shetti, ${ }^{*[b]}$ Soumen Basu, ${ }^{[c]}$ Kakarla Raghava Reddy, ${ }^{*[d]}$ and Tejraj M. Aminabhavi ${ }^{[e]}$

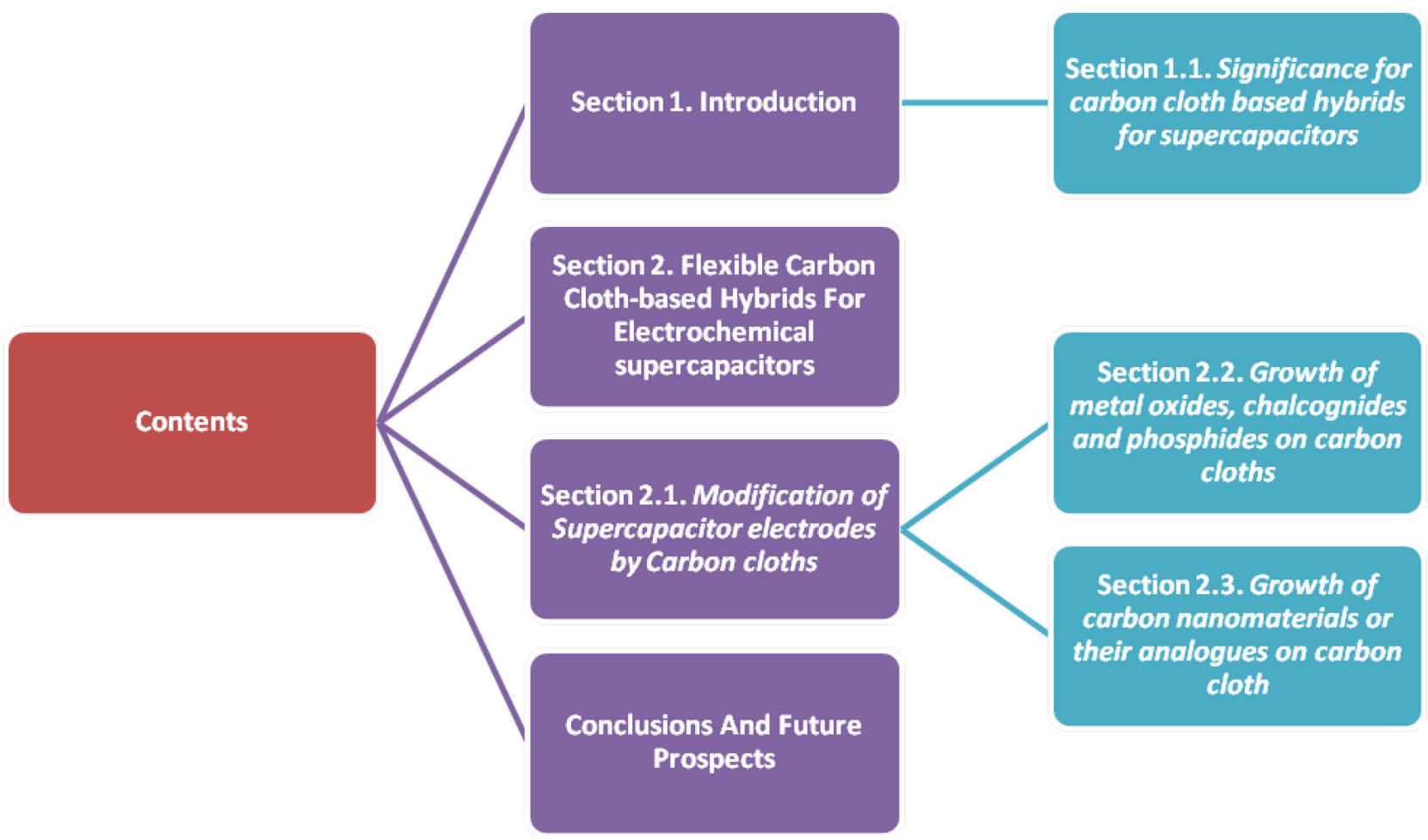


Carbon cloths are the important materials composed of woven carbon fibres having the diameters in the range of 5-10 $\mu \mathrm{m}$. These materials have been investigated for innumerable applications such as supercapacitors (symmetric and asymmetric), batteries, solar cells, and catalysis. They are found to be the best supports as supercapacitive materials by providing high surface area, conductivity and flexibility compared to much widely used substrate materials such as $\mathrm{Ni}$ foam and 1D Fe nanowires. High conductivity and surface area of carbon cloths enable ion diffusion and cause decrease in charge transfer resistance, resulting in an increase of specific capacitance of specific electrodes. Several supercapacitive metal oxides, chal- cogenides, phosphides, MXenes, carbon nanotubes, graphene, and conductive polymers have been incorporated into carbon cloths to improve their energy storage activity. Further modification of carbon cloth surface via oxidation, doping and by the growth of different nanostructures is also helpful as it increases the electroactive surface area necessary for electrochemical interaction. The present review mainly focuses on the development of flexible supercapacitors using carbon clothbased substrate materials. Such flexible supercapacitors can be further utilized for an uninterrupted and steady power supply to wearable and portable electronic devices.

\section{Introduction}

The extensive use of limited fossil fuels resources has given rise to environmental pollution and energy crises, ${ }^{[1,2]}$ thereby leading to increased demand for developing renewable and sustainable energy sources such as energy from the sunlight. However, the intensity of sunlight varies from region to region on the mother earth as it is more intense at the equator, whose intensity decreases as we move toward the polar regions. It also varies with time as it is more intense in the afternoon and unavailable at night. ${ }^{[3,4]}$ Similar issues are also faced with devices, which harness other renewable energy sources like wind energy as the wind flow, where the power is not uniform. This may lead to an improper power supply, which may result in the malfunctioning of electrical appliances and it will be difficult for steady power supply to longer distances. To overcome such issues, the energy obtained from fluctuating renewable sources should be stored either as an electrical and electrochemical form for its proper utilization and supply. For these reasons, devices like supercapacitors and batteries have gained immense attention in electrical and electrochemical storage of energy obtained from the renewable sources. ${ }^{[5]}$

The working principle of batteries involves redox charge/ discharge processes at different electrodes. ${ }^{[6-10]}$ The redox processes during the charging lead to the storage of electrical

[a] Dr. A. Mishra

Department of Chemistry, Bilkent University,

Cankaya, Ankara-06008, Turkey

[b] Prof. N. P. Shetti

Center for Electrochemical Science \& Materials,

Department of Chemistry, K. L. E. Institute of Technology,

Gokul, Hubballi-580030,

Affiliated to Visvesvaraya Technological University, Karnataka, India

E-mail:npshetti@gmail.com

[c] Prof. S. Basu

School of Chemistry and Biochemistry

Thapar Institute of Engineering \& Technology,

Patiala, Punjab-147004, India

[d] Dr. K. Raghava Reddy

School of Chemical and Biomolecular Engineering,

The University of Sydney,

Sydney, NSW 2006, Australia

E-mail: reddy.chem@gmail.com

[e] Prof. T. M. Aminabhavi

Pharmaceutical Engineering, Sonia College of Pharmacy,

Dharwad 580 002, Karnataka, India energy as the chemical energy at the electrodes, which can be reconverted to the electric current during the discharge process when needed. ${ }^{[7,11]}$ On the other hand, in supercapacitors, the charge gets accumulated at the electrode/electrolyte interface during the charging processes, resulting in the generation of a static electric field/potential between the electrodes. ${ }^{[12-15]}$ There have been extensive research efforts on both batteries and supercapacitors, but supercapacitors have some merits over the batteries such as high charge/discharge rates, high operating safety, long cycle life and high power density. ${ }^{[7,11,12,14,16]}$ As of today, no reports are available in the literature on flexible carbon cloths-based electrode materials for energy storage applications.

This review discusses the current developments in the synthetic methodologies of various flexible carbon cloth-based hybrid electrodes and enhancement in their physicochemical characteristics along with electrochemical properties. In addition, their potential applications for electrochemical energy storage supercapacitors are also discussed.

\subsection{Significance of Carbon Cloth-based Hybrid Materials for Supercapacitors}

Carbon cloths are composed of carbon fibers with a diameter of around $5-10 \mu \mathrm{m} .{ }^{[17]}$ They are highly conductive, flexible, mechanically strong, hydrophobic, have low cost and are ecofriendly. ${ }^{[18]}$ Their good biocompatibility makes them very promising in biomedical applications. Additionally, there are several applications of carbon cloths such as in catalysis, ${ }^{[19]}$ water splitting, ${ }^{[20]}$ wastewater treatment ${ }^{[21,22]}$ and air purification. ${ }^{[23]}$ On the other hand, their 3D structures and faster transportation of ions make them desirable materials for their use as electrodes in batteries, ${ }^{[24,25]}$ supercapacitors ${ }^{[26]}$ and solar cells. ${ }^{[27]}$ Innumerable strategies have been adopted to further enhance their surface area and porosity like chemical treatment, exfoliation, ${ }^{[18]}$ functionalization with appropriate chemical groups, elemental doping, and coupling with hierarchical 3D porous structures. ${ }^{[2]}$ Among these, chemical treatment or activation has been widely employed to impart high surface area and porosity to carbon cloths, which is necessary for their applications as supercapacitors, adsorbents, and catalysis. For supercapacitor applications, carbon cloths have been found to 
act as excellent substrates as they provide high conductivity, surface area and enable ion diffusion, which leads to a decrease in charge transfer resistance and increases in specific capacitance of the resultant electrode. These are highly promising compared to the widely used supercapacitor substrate materials like $\mathrm{Ni}$ foam and Fe nanostructures ${ }^{[14,15,28-32]}$

Chemically treated or activated carbon cloths (ACCs) act as effective adsorbents for inorganic ions and organic molecules. Also, the ACC adsorbents have high reusability as the adsorption sites can be regained by desorption of the adsorbed constituents. ${ }^{[17]}$ Although ACCs are mostly prepared via chemically treating the carbon cloths, there are a number of procedures reported by which ACCs can be directly obtained from the carbon-rich precursors such as viscous rayon by carbonization processes, chemical, physical activation via $\mathrm{CO}_{2}$ and steam. ${ }^{[33-35]}$ In a recent report, Delgado et al. ${ }^{[21]}$ prepared ACCs by taking natural Henequen and jute fibers as precursors. In the preparation process, three types of activation processes were investigated on Henequen and jute fibers such as physical activation by steam and $\mathrm{CO}_{2}$ and chemical activation with $\mathrm{ZnCl}_{2}$. It was observed that the pore structure and distribution of as prepared ACCs was dependent upon the activation process. It was found that chemical activation resulted in the formation of microporous structure, while the physical activation using steam and $\mathrm{CO}_{2}$ imparts a wider pore distribution from the micropores to a small number of mesopores. Although the henequen and jute fibers have similar carbon content the

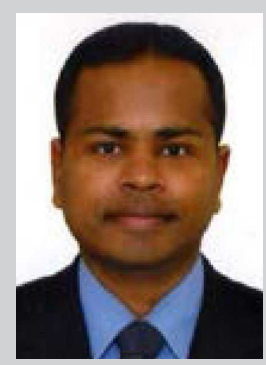

Dr. Kakarla Raghava Reddy received his PhD degree in Chemistry from Kyungpook National University, which is ranked within the first five institutes of higher education in South Korea, after first receiving his master's degree in Chemistry at Sri Krishnadevaraya University, Andhra Pradesh, India. He has received highly prestigious international postdoctoral fellowships such as JSPS (Japan), and Vice-Chancellor Postdoctoral Fellowship (The University of Sydney, Sydney, Australia). He is currently working as a senior research fellow and his specialities are synthetic polymer chemistry, macromolecular and materials chemistry, nanotechnology, focusing on polymer synthesis and modifications, structure-propertyapplication relationship of novel synthetic polymers, advanced functional nanomaterials for diverse applications in energy, catalysis, biomedical fields, and related areas. He has published numerous papers in these areas in various leading journals, conference proceedings and book chapters in books.

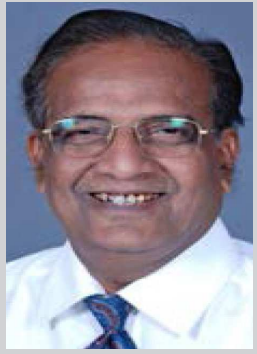

Tejraj M. Aminabhavi is the Director of research at Soniya College of Pharmacy, Dharwad, India. He obtained his PhD from the University of Texas at Austin in 1979 and was a postdoctoral associate at Clarkson University, New York during 1980-1982. He taught chemistry for 36 years at Karnatak University, Dharwad, India. He was the director of center of excellence in polymer science during 20022007. Dr. Aminabhavi was the scientific advisor to Reliance Life Sciences, Mumbai, India. Dr. Aminabhavi has a distinct career of having published over 750 research papers, a textbook published by Wiley (2002), and three US Patents on polymeric membranes. His research publications received citations up to 35000 with an h-index of 87. Dr. Aminabhavi has been the visiting scientist to University of Texas at Dallas, Lamar University, Texas, UT Southwestern Medical Center at Dallas, Texas State University, San Marcos, and Cambridge University (UK) in addition to universities in France, Taiwan and Korea. 
ACCs prepared from the latter had high mechanical strength and flexibility.

The ACCs prepared from henequen fibers were brittle, which was due to the dissembling nature of the constituent carbon fibers. Due to large surface area and porosity, the ACCs have been extensively investigated for their role as electrodes in supercapacitors. Apart from surface activation growth of different carbon-based nanostructures onto carbon cloth surface provide a large amount of electro-active sites, which are beneficial for supercapacitor applications. The main scope of the present review is to consider a high emphasis on different strategies for the fabrication of flexible carbon cloth-based electrodes for flexible and bendable supercapacitors. Carbon cloths tend to act as excellent substrates or support materials for other supercapacitor materials, which show EDLC behavior like MXenes and pseudo-capacitive behavior like metal oxides, chalcogenides, phosphides, conducting polymers, Metal-organic frameworks, core-shell structures, etc.

\section{Flexible Carbon Cloth-based Hybrids For Electrochemical Supercapacitors}

\subsection{Modification of Supercapacitor Electrodes by Carbon Cloths}

Successful application of low-cost materials derived from carbon in energy storage depends upon the exploration of cost-efficient processes and fabrication techniques, which should be quite convenient to scale-up. There are a number of recent investigations on the application of carbon cloths in supercapacitors. The carbon cloths have been reported to act as excellent supports to a large number of pseudo-capacitive metal oxides, chalcogenides, and phosphides. As Faradaic supercapacitive electrodes, the transition metal oxides have been extensively incorporated upon the electrically conductive carbon materials due to their high theoretical storage capacity and reversibility. ${ }^{[36,37]} \mathrm{MnO}_{2}$ has been extensively supported upon the carbon cloth substrate to fabricate flexible supercapacitor electrodes..$^{[5]}$

An inexpensive natural flex fiber weaved textile was taken as raw material by $\mathrm{He}$ et al. ${ }^{[38]}$ to prepare a binder-free and flexible supercapacitor electrode. The textile cloth was carbonized to obtain carbon fiber cloth electrode. The as-prepared carbon fiber cloth shows poor super-capacitive performance with a specific capacitance of $0.78 \mathrm{~F} / \mathrm{g}$, which was mainly due to its low surface area. However, it exhibited good stability and almost $100 \%$ of specific capacitance was retained after 10000 cycles at a current density of $5 \mathrm{~A} / \mathrm{g}$. It also possessed a rapid frequency response with a relaxation time of $39.1 \mathrm{~ms}$ and low resistance, making it a very promising substrate to incorporate other super-capacitive materials. In order to enhance the supercapacitive performance of carbon cloth, highly pseudo-capacitive $\mathrm{MnO}_{2}$ nanosheets ${ }^{[39,40]}$ were mounted over the carbon cloths (Figure 3(a)) by in situ redox reaction process between carbon cloths and $\mathrm{KMnO}_{4}$. The capacitance of the resulting electrode enhanced upon $\mathrm{MnO}_{2}$ incorporation, and capacitance of $683.73 \mathrm{~F} / \mathrm{g}$ was obtained at $2 \mathrm{~A} / \mathrm{g}$ with an energy density of $46.54 \mathrm{Wh} / \mathrm{kg}$. The in situ growth of $\mathrm{MnO}_{2}$ nanosheets on carbon cloth led to a decrease in contact resistance, thereby resulting in rapid electron transfer.

Carbon cloth was functionalized with coral-like $\mathrm{MnO}_{2}$ nanostructures through green hydrothermal approach by controlling the hydrothermal reaction time and temperatures and was used as an excellent flexible electrode material for applications in electrochemical energy storage systems.$^{[5]}$ Novel $\mathrm{CC} / \mathrm{MnO}_{2}$ hybrid electrode showed super capacitance of $467 \mathrm{~F} / \mathrm{g}$ at a current density of $1 \mathrm{~A} / \mathrm{g}$ with capacity retention of $99.7 \%$ and columbic efficiency of $99.3 \%$ after 5000 cycles. The electrochemical device fabricated with $\mathrm{CF} / \mathrm{MnO}_{2}$ nanohybrid showed an excellent energy density of $20 \mathrm{~W} \mathrm{~h} / \mathrm{kg}$ at a power density of $0.175 \mathrm{~kW} \mathrm{~h} / \mathrm{kg}$.

Fan et al. ${ }^{[41]}$ deposited $\mathrm{MnO}_{2}$ and pyrrole composite on the carbon cloth via facile in situ electrodeposition technique, which (Figure 3 (b)) led to the formation of needle-like $\mathrm{MnO}_{2}$ structure upon the flexible electrode. The multi-layered structure of the electrode possessed a specific capacitance of $325 \mathrm{~F} /$ $\mathrm{g}$ at a current density of $0.2 \mathrm{~A} / \mathrm{g}$. Feng et al. ${ }^{[42]}$ prepared $\mathrm{a}$ carbon cloth-based electrode coated with $\mathrm{MnO}_{x}$ nanostructures such as $\mathrm{MnO}_{2}$ nanosheets and $\mathrm{MnOOH}$ nanorods. The electrode fabricated from carbon cloths coated with $\mathrm{MnO}_{2}$ nanosheets delivered a specific capacitance of about $429.2 \mathrm{~F} / \mathrm{g}$, which was much higher than that of the electrode prepared by coating carbon cloths with $\mathrm{MnOOH}$ nanorods $(10.3 \mathrm{~F} / \mathrm{g}$ ) at a current density of $0.2 \mathrm{~A} / \mathrm{g}$. The low specific capacitance of electrode prepared from $\mathrm{MnOOH}$ nanorods was attributed to the longer ion diffusion length in the nanorods and their aggregation. The effect of morphology and the surface-related features of the deposited metal oxides like porosity are also of significant importance to upsurge the energy storage capability of a supercapacitor.

The multiple valence states and unique layered structure of metal oxide like $\mathrm{V}_{2} \mathrm{O}_{5}$ play a significant role in efficient ion diffusion high energy density. ${ }^{[43]}$ The $\mathrm{V}_{2} \mathrm{O}_{5}$ nanostructures were incorporated onto activated carbon cloths (ACCs) by a simple ion-exchange column process by Zhou et al. ${ }^{[4]}$ The $\mathrm{V}_{2} \mathrm{O}_{5}$ nanostructures promoted the in situ polymerization of indole monomer which resulted in the formation of bamboo-like $\mathrm{V}_{2} \mathrm{O}_{5} /$ polyindole@activated carbon cloth $\left(\mathrm{V}_{2} \mathrm{O}_{5} / \mathrm{PIn} @ A C C\right)$ electrode. The introduction of polyindole (PIn) in direct contact with $\mathrm{V}_{2} \mathrm{O}_{5}$ not only prevents its dissolution into the electrolyte due to its high corrosion resistance but also due to its intrinsic conductivity provides facile electron transport. ${ }^{[45]}$ Apart from being conductive, PIn has an excellent storage ability, thermal stability and electrochemical reversibility. ${ }^{[46]}$ On the other hand, conducting polymers and metal oxides due to their pseudocapacitive nature usually exhibit large specific capacitance and energy density, making them ideal positive electrode materials. ${ }^{[47,48]}$

The carbon-based materials due to their complementary operating voltage windows with various positive electrodes are used as negative electrodes. Hence, the as-prepared $\mathrm{V}_{2} \mathrm{O}_{5} /$ PIn@ACC was used as a positive electrode along with $\mathrm{rGO} @ A C C$ 
(a)

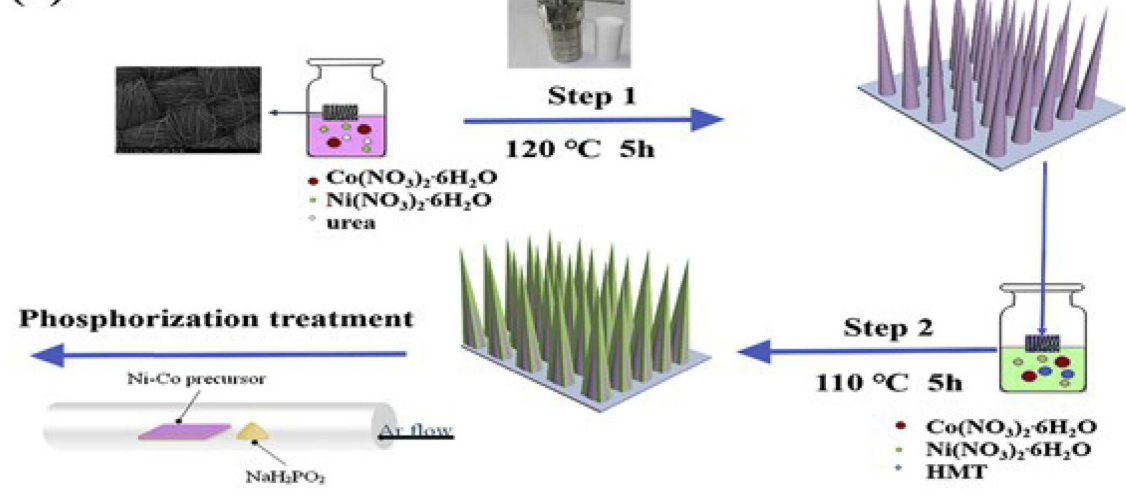

(b)

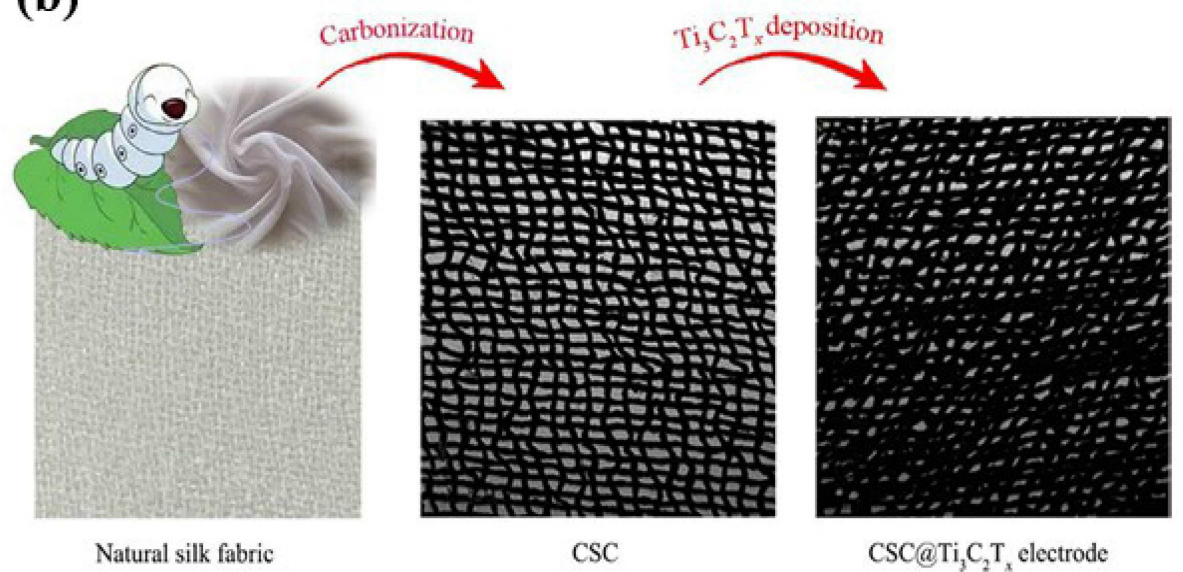

Figure 1. (a) Schematic representation for the preparation of NiCoP@NiCoP core-shell arrays on carbon cloth, reprinted with permission from Ref. [92]; (b) preparation of Silk fibre derived carbon cloth/ $\mathrm{Ti}_{3} \mathrm{C}_{2} \mathrm{~T}_{x}$ composite electrode. Reprinted with permission from Ref. [103].

as a negative electrode to construct an asymmetric supercapacitor. The more pseudo-capacitive behavior of Pln and $\mathrm{V}_{2} \mathrm{O}_{5}$ led to the high operating voltage of the device and also a maximum cell capacitance of $275.5 \mathrm{~F} / \mathrm{g}$ along with high energy and power density of $38.7 \mathrm{Wh} / \mathrm{kg}$ and $0.9 \mathrm{~kW} / \mathrm{kg}$ was obtained. Due to the high theoretical capacitance of $3625 \mathrm{~F} / \mathrm{g}$ and suitable working voltage window, $\mathrm{Fe}_{2} \mathrm{O}_{3}$ has been incorporated on carbon cloths-based electrodes. ${ }^{[49]}$ Zhang et al. ${ }^{[50]}$ carried out the synthesis of successfully designed three-layered core-shell sandwiched structure comprising of carbon nanotubes/ $\mathrm{Fe}_{2} \mathrm{O}_{3} @$ carbon arrays supported on carbon cloth substrate. The carbon array and carbon nano-tube both play the role of increasing the surface area, conductivity, restraining of active materials, enhancing the energy storage performance and longterm stability. They also act as the outer protective conductive layers for $\mathrm{Fe}_{2} \mathrm{O}_{3}$ and prevent the diffusion of $\mathrm{Fe}$ based intermediate oxide and hydroxide. The carbon nanotubes/ $\mathrm{Fe}_{2} \mathrm{O}_{3} @$ carbon arrays supported onto carbon cloth substrate electrode exhibits specific capacitance of about $787.5 \mathrm{~F} / \mathrm{g}$, which makes it a highly promising negative electrode for highperformance supercapacitors.

Chen et al. ${ }^{[51]}$ in their report demonstrated the use of $\alpha$ $\mathrm{Fe}_{2} \mathrm{O}_{3}$ supported on carbon cloth as a negative supercapacitor electrode. Tetsubo like $\alpha-\mathrm{Fe}_{2} \mathrm{O}_{3} / \mathrm{C}$ nano-arrays with hollow structures composing of $\alpha-\mathrm{Fe}_{2} \mathrm{O}_{3}$ nano-crystals and carbon nanoparticles with plenty of mesopores between them were supported upon carbon cloths. The hollow porous structure and presence of carbon nanoparticles in $\alpha-\mathrm{Fe}_{2} \mathrm{O}_{3} / \mathrm{C}$ nano-arrays not only promotes the acceleration of electrons and ions but also increase the active sites for energy storage. The electrode delivered a specific super-capacitance of about $430.8 \mathrm{mF} / \mathrm{cm}^{2}$ (391 F/g) at a current density of $1 \mathrm{~mA} / \mathrm{cm}^{2}$. The carbon cloth supported $\alpha-\mathrm{Fe}_{2} \mathrm{O}_{3} / \mathrm{C}$ nano-arrays were used to construct an asymmetric supercapacitor where it was used as a negative electrode with $\mathrm{MnO}_{2}$ as the positive electrode and the device exhibited an energy density of $0.64 \mathrm{mWh} / \mathrm{cm}^{3}$ at a power density of $14.8 \mathrm{~mW} / \mathrm{cm}^{3}$. Recently reported porous $\mathrm{Fe}_{2} \mathrm{O}_{3}$ nanospheres incorporated upon activated carbon cloth (ACC) showed large super-capacitance of $2775 \mathrm{mF} / \mathrm{cm}^{2}$ at a current density of $1 \mathrm{~mA} / \mathrm{cm}^{2}(1500 \mathrm{~F} / \mathrm{g}$ at $0.5 \mathrm{~A} / \mathrm{g})$ which was more than previously reported $\mathrm{Fe}_{2} \mathrm{O}_{3}$ supported carbon cloth electrodes. ${ }^{[52]}$ The synergistic effect of large surface area $\left(99.1 \mathrm{~m}^{2} / \mathrm{g}\right)$ and porosity of $\mathrm{Fe}_{2} \mathrm{O}_{3}$, and good electrical conductivity of ACC, lower diffusion barrier of $\mathrm{Fe}_{2} \mathrm{O}_{3}$ and exposed surface electronegativity were attributed to better supercapacitor performance. In addition to this, it also has excellent stability and retains $92 \%$ of capacitance in 10000 cycles. The symmetric supercapacitor 

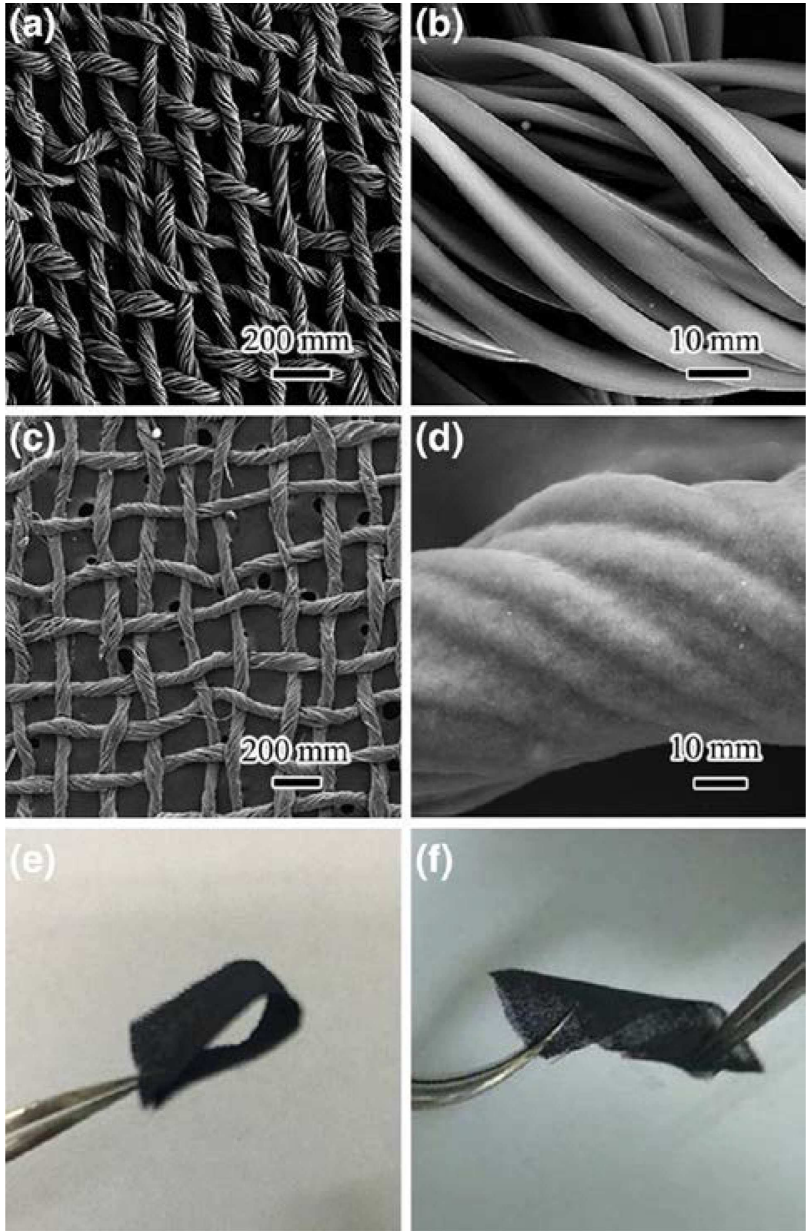

Figure 2. (a)-(d) SEM images of carbon cloth prepared by carbonization of silk, (e) and (f) photographs of bent and twisted electrode Reprinted with permission from Ref. [102].

prepared from the electrode delivers an energy density of $9.2 \mathrm{mWh} / \mathrm{cm}^{3}$ at power density $12 \mathrm{~mW} / \mathrm{cm}^{3}$.

MXenes are two-dimensional transition metal carbides and carbon nitrides are recently explored and have shown much potential for energy storage applications. ${ }^{[3-57]}$ Among the MXenes, $\mathrm{Ti}_{3} \mathrm{C}_{2} \mathrm{~T}_{x}$ is highly investigated, and it can be obtained by the selective etching of $\mathrm{Al}$ from $\mathrm{Ti}_{3} \mathrm{AlC}_{2}$, which is a layered ternary carbide material, called the MAX phase. ${ }^{[57,58]}$ The sites left after etching of $\mathrm{Al}$ are spontaneously filled with $\mathrm{O}, \mathrm{F}, \mathrm{OH}$ or $\mathrm{H}$ groups which results in a general formula $\mathrm{Ti}_{3} \mathrm{C}_{2} \mathrm{~T}_{x}$, where $T_{x}$ denotes the groups, which fill the etched sites. ${ }^{[59]}$ As MXenes have metallic conductivity, hydrophilic nature, excellent ion intercalation behavior, these have been reported to have a high capacitance, which has exceeded those of the previously reported electrode materials. ${ }^{[60,61]}$ However, these are not mechanically strong to withstand bending for a long time, thus limiting their applications in flexible super-capacitors and also MXenes having both high strength and capacitance are difficult to obtain and thus, it remains a challenge. In order to impart some flexibility to MXenes carbon-based materials like carbon cloths obtained from naturally existing materials have received widespread attention due to their good electrical conductivity and mechanical strength. ${ }^{[62]}$

$\mathrm{Hu}$ et al. ${ }^{[57]}$ prepared carbon cloth derived from silk by carbonization at high temperature upon which $\mathrm{Ti}_{3} \mathrm{C}_{2} \mathrm{~T}_{x}$ Mxene was supported by the solution processing method ${ }^{[63]}$ (Figure $1(b))$. Silk is famous for its mechanical strength, ${ }^{[64]}$ which is retained by the as-prepared carbon cloth. SEM images (< Figure 2(a)-(d)) show that the smooth carbon fibers were obtained from the carbonization of silk after the removal of impurities. After MXene deposition the surface of carbon cloth was uniformly and densely coated with $\mathrm{Ti}_{3} \mathrm{C}_{2} \mathrm{~T}_{x}$ film with perfect adhesion between the two allowing the electrode to attain much flexibility for bending and twisting (Figure 2(e) and (f)). The electrochemical behavior of silk-derived carbon cloth as observed from CV was enhanced after the deposition of $\mathrm{Ti}_{3} \mathrm{C}_{2} \mathrm{~T}_{x}$ and the areal capacitance values were obtained to be in the range $32-362 \mathrm{mF} / \mathrm{cm}^{2}$ at a scan rate of $2 \mathrm{mV} / \mathrm{s}$, which are higher than the previously reported MXene-based electrodes. Also, no significant change in electrochemical behavior was observed by bending and deforming the all-solid-state super-capacitors fabricated from the as-prepared electrode.

\subsection{Growth of Metal Oxides, Chalcogenides, and Phosphides on Carbon Cloths}

It was clearly demonstrated in a report by Shinde et al. ${ }^{[65]}$ in which different morphologies of $\mathrm{MnO}_{2}$ such as mesoporous weirds, leaf-like veins and microrods were grown upon carbon cloth substrate by a hydrothermal process carried out at different temperatures. The influence of temperature upon reaction kinetics led to the formation of different morphologies of $\mathrm{MnO}_{2}$. Among the as-deposited structures, the mesoporous $\mathrm{MnO}_{2}$ weirds were found to possess desired properties for supercapacitor application due to their high surface area, mesoporous nature and a large number of electroactive sites for the adsorption of ions.

Chen et al. ${ }^{[66]}$ used electrically conductive and hydrophilic carbon cloths (HCC) as substrates upon which electroactive polypyrrole and $\mathrm{MnO}_{2}$ were directly grown. The growth process was carried out by the means of controlled electrochemical deposition method (Figure 3(c)), which results in the formation of $\mathrm{MnO}_{2} @ \mathrm{HCC}$ and PPy@HCC. These were used to construct an all solid flexible $\mathrm{MnO}_{2} @ \mathrm{HCC} / / \mathrm{PPy} @ \mathrm{HCC}$ asymmetric supercapacitor as illustrated in Figure 3(a) and showed good flexibility upon bending and twisting to different angles (Figure $3(\mathrm{~b})$ and (c)). The two electrode materials separately showed different electrochemical behaviors where the CV of $\mathrm{MnO}_{2} @ \mathrm{HCC}$ exhibited quasi-rectangular profile showing good capacitive and that of PPy@HCC showed the pseudo-capacitive feature (Figure $3(\mathrm{~d})$ ). However, the CV (Figure $3(\mathrm{e})$ ) of asymmetric supercapacitor $\mathrm{MnO}_{2} @ \mathrm{HCC} / / \mathrm{PPy} @ \mathrm{HCC}$ exhibits distorted quasi-rectangular shape at different scan rates with large area revealing about its large capacitance. The shape of CV remained unchanged at higher scan rates indicating about typical reversible Faradaic pseudo-capacitance. Also, the CV profiles remained significantly unchanged even upon bending the 
(a)
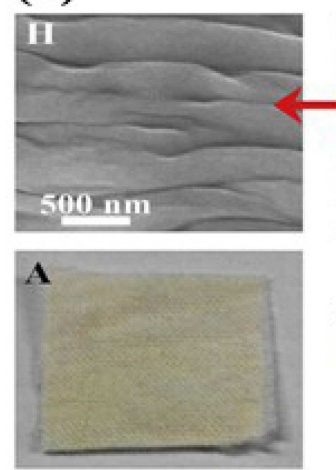

Flax textile

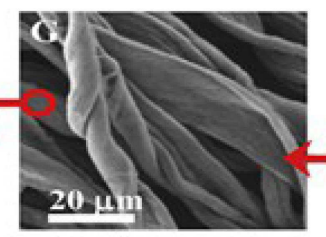

\section{Carbonization}
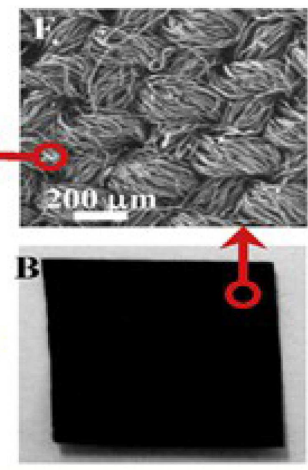

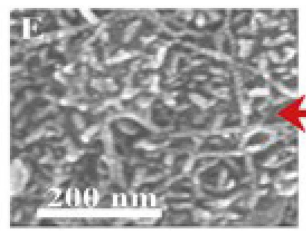

$\mathrm{MnO}_{2}$ deposition

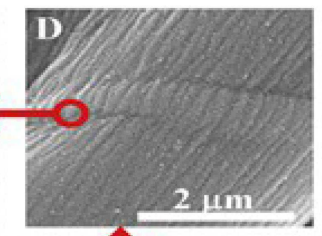

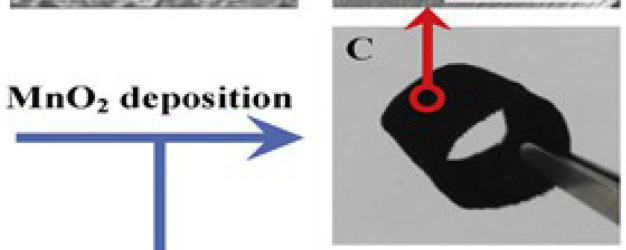

$$
4 \mathrm{MnO}_{4}{ }^{-}+3 \mathrm{C}+\mathrm{H}_{2} \mathrm{O} \rightarrow 4 \mathrm{MnO}_{2}+\mathrm{CO}_{3}{ }^{2-}+2 \mathrm{HCO}_{3}{ }^{-}
$$

(b)

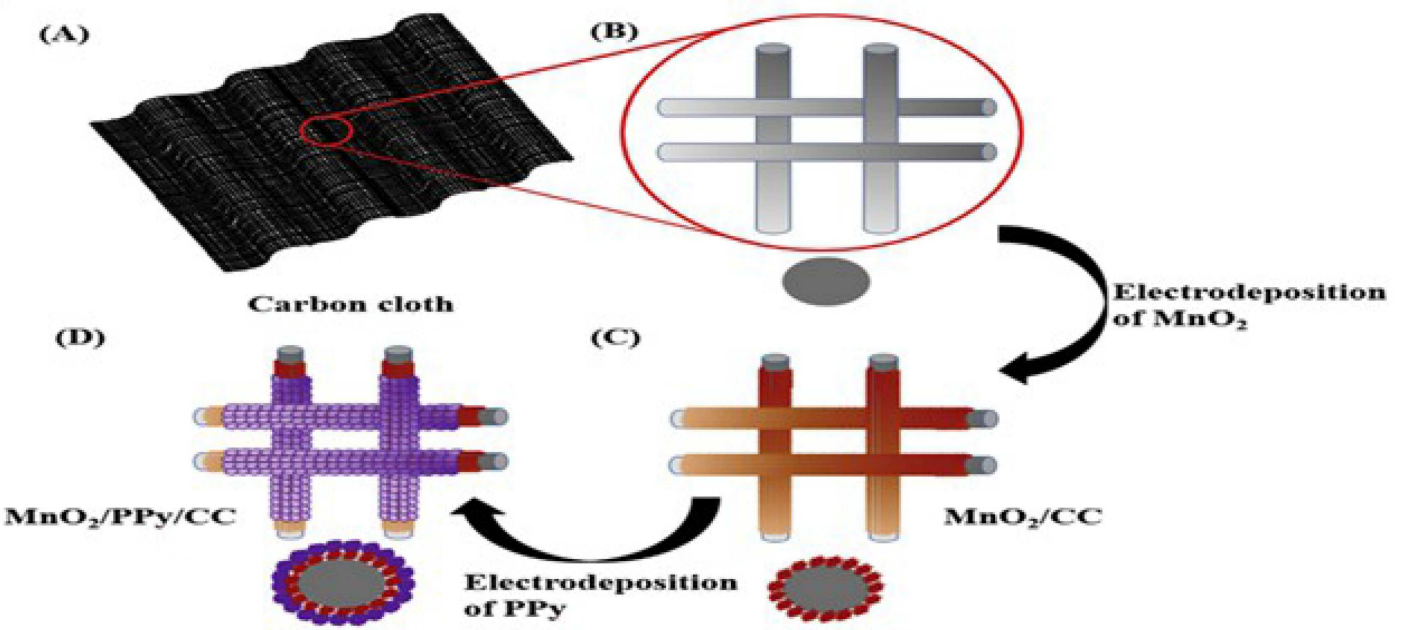

(c)

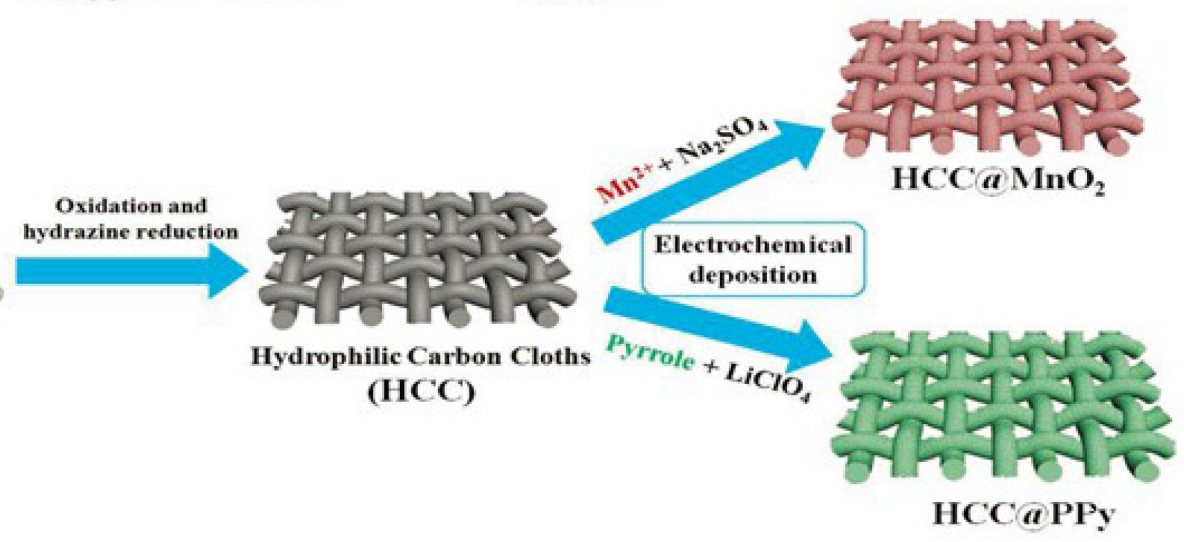

Figure 3. (a) Preparation of carbon cloth by carbonization of Flax textile and deposition of $\mathrm{MnO}_{2}$ nanosheets. Reprinted with permission from Ref. [38]. (b) In situ electrodeposition of $\mathrm{MnO}_{2}$ and polypyrrole over carbon cloth. Reprinted with permission from Ref. [41] (c) preparation and growth of HCC and growth of $\mathrm{MnO}_{2}$ or polypyrrole over its surface. Reprinted with permission from Ref. [66].

device to $180^{\circ} \mathrm{C}$, which showed much better mechanical stability (Figure 3(f)). The energy and power densities obtained from the device were about $420.5 \mathrm{~W} / \mathrm{kg}$ and $28.2 \mathrm{Wh} / \mathrm{kg}$, which is reported to be higher than previous devices. Though the theoretical capacitances of transitional metal oxides are quite high the experimentally obtained values are low due to low effective surface area and low conductivity. ${ }^{[67]}$ Since then, carbon cloths have gained tremendous attention as current collectors in metal oxide-based supercapacitor electrodes due to their good electrical conductivity. ${ }^{[68]}$

Apart from $\mathrm{MnO}_{2}$, there have been several other metallic and bimetallic oxides such as $\mathrm{V}_{2} \mathrm{O}_{5}{ }^{[44]} \mathrm{Fe}_{2} \mathrm{O}_{3}{ }^{[29,50-52]} \mathrm{NiO},{ }^{[69,70]}$ 
$\mathrm{MoO}_{3}{ }^{[67,71,}{ }^{72]} \mathrm{ZnO},{ }^{[69,73,}{ }^{74]} \mathrm{WO}_{3}{ }^{[75]} \mathrm{CoMoO}_{4}{ }^{[76,77]} \mathrm{NiMoO}_{4}{ }^{[78]}$ $\mathrm{NiCO}_{2} \mathrm{O}_{4}{ }^{[78,79]} \mathrm{FeCO}_{2} \mathrm{O}_{4},{ }^{[80]}$ which have been deposited onto the carbon cloths to fabricate supercapacitor electrodes. Recently, ZnO@C@NiO core-shell nanorods arrays were grown upon carbon cloth substrate. ${ }^{[69]}$ The conductive carbon layer derived from glucose between $\mathrm{ZnO}$ and $\mathrm{NiO}$ protected $\mathrm{ZnO}$ from corrosion in alkaline solution and increased the conductivity of the electrode material. Here, $\mathrm{ZnO}$ contributes to electron transport and ion diffusion. An asymmetric supercapacitor was fabricated using the carbon cloth supported ZnO@C@NiO coreshell nanorods as the cathode and commercial graphene as anode delivered energy density of $35.7 \mathrm{Wh} / \mathrm{Kg}$ at a power density of $380.9 \mathrm{~W} / \mathrm{Kg}$ with cycling stability by retaining $87.5 \%$ capacitance after 10000 charges/discharge cycles. Rational design and preparation of hollow core-shell structures for better supercapacitor performance is still a challenging task.

Cao et al. ${ }^{[73]}$ have developed a simple and effective process called root etch wrap method to synthesize hollow core-shell heterostructured electrodes. In this process (Figure $4(A)$ ) the $\mathrm{ZnO}$ hollow spheres acted as roots and are grown upon activated carbon cloth surface by the in situ process. The $\mathrm{ZnO}$ hollow spheres act as templates for the generation of ZIF-8 metal-organic frameworks (MOFs) to form ZnO@ZIF-8-CC coreshell structure. Finally, polyaniline (PANI) is loaded by electro- polymerization of aniline to form PANI/ZnO@ZIF-8-CC core-shell structured electrode. Here, the MOFs, which belong to the type of solid crystalline materials having intrinsic porosity provide large surface area accessible to the electrolyte. ${ }^{[81-83]}$ The heterostructured and hollow PANI/ZnO@ZIF-8-CC core-shell electrode combines well the synergistic effects of all the components which result in increased mechanical strength, porosity, and electrical conductivity. It was observed from SEM (Figure 4(B)) that the ZnO hollow spheres uniformly cover the surface of carbon cloths. On the other hand, both SEM and TEM (Figure $4(B)$ ) confirm the formation of hollow $\mathrm{ZnO}$ spheres the coreshell structure with $\mathrm{ZnO}$ as core and ZIF-8 and PANI as shells upon carbon cloth substrate. The PANI in electrode imparts hydrophilic nature which was observed from contact angle measurements in which small contact angle of $32.9^{\circ}$ was observed for PANI/ZnO@ZIF-8-CC when compare to that of ZnO@ZIF-8-CC $\left(135.3^{\circ}\right)$ (Figure 4(a)). The hydrophilicity was also attributed to the presence of amido and quaternary ammonium species as observed from high-resolution XPS spectra of N1 s (Figure 4(b)). Also, the peaks related to positively charged imine and protonated amine were also observed in XPS which can be due to protonation of PANI due to electro-oxidation during polymerization. The high conductivity together with high electrolyte accessible surface area and porosity makes PANI/ (a)

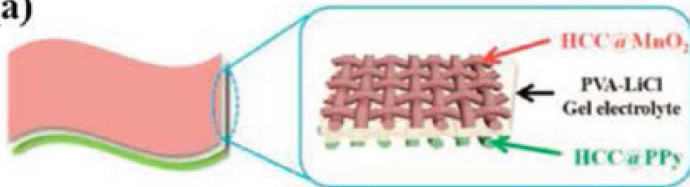

$\mathrm{HCCa} \mathrm{InO}_{2} / \mathrm{HCC}$ a PPy ASC
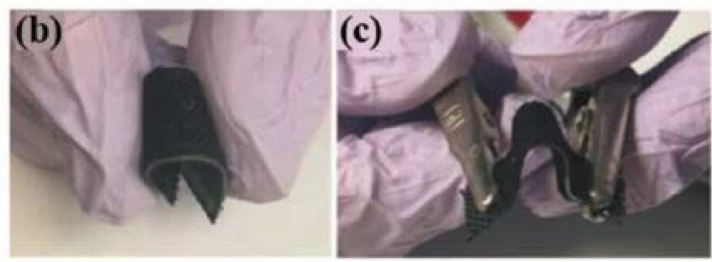

(e)

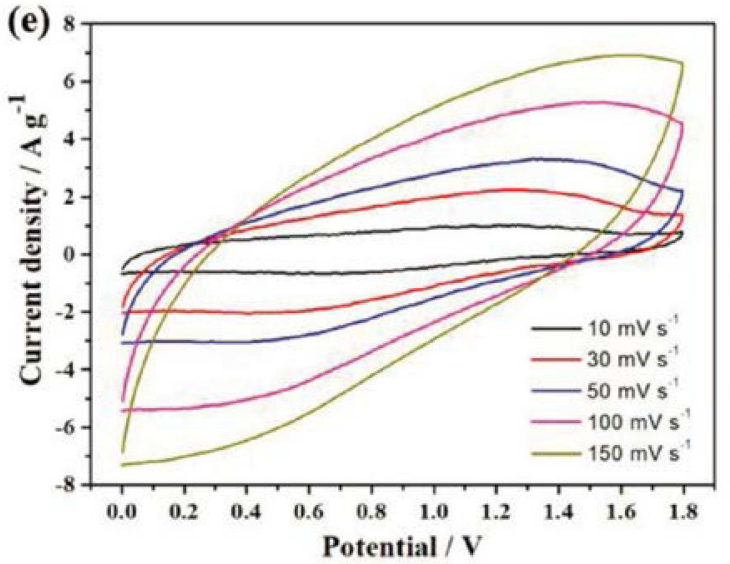

(d)

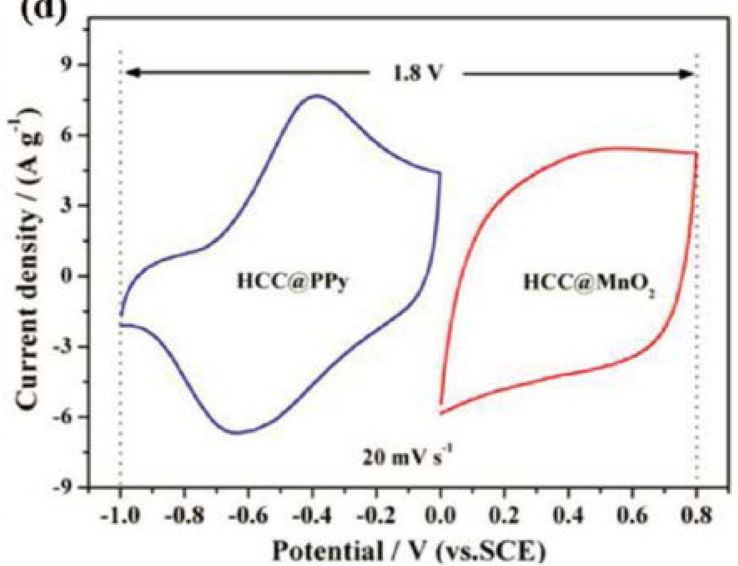

(f)

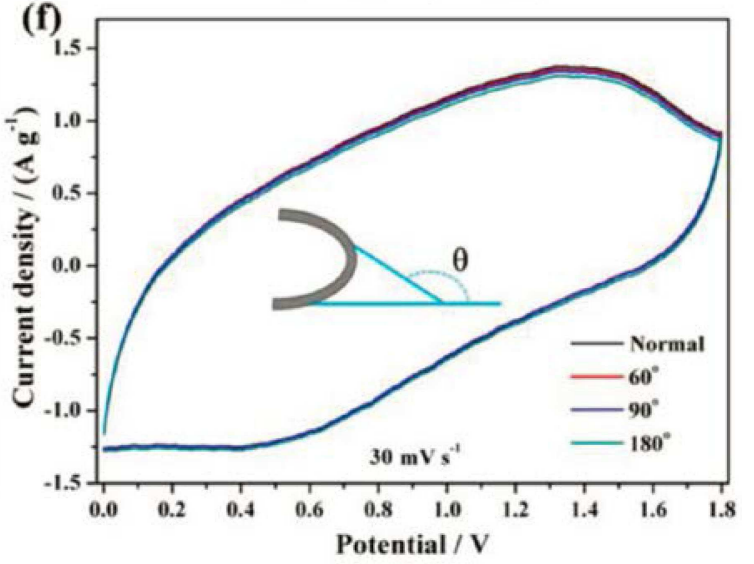

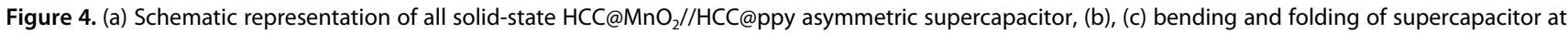

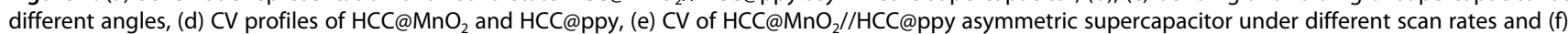
after bending at different angles. Reprinted with permission from Ref. [66]. 
ZnO@ZIF-8-CC much better electrode for supercapacitor application. The mirror image current response and the presence of redox reaction peaks reveal the co-existence of EDLC and pseudo-capacitance behavior. ${ }^{[84]}$ The pseudo-capacitance effect led to the distortion in triangular charge/discharge profiles of the electrode. The higher CV area and redox peak intensity than other electrodes indicate better capacitance and fast redox kinetics. The electrode exhibits a specific areal capacitance of $4389 \mathrm{mF} / \mathrm{cm}^{2}$ at a current density of $5 \mathrm{~mA} / \mathrm{cm}^{2}$ and $82.4 \%$ of it is retained due to the hydrophilicity of PANI which makes electrolyte ions accessible to electrode surface. ${ }^{[85]}$ The capacitance is mainly due to the synergistic effect of high surface area and porosity of ZnO@ZIF-8, electrical conductivity of carbon cloth and pseudo-capacitance of PANI. The high conductivity imparted by carbon cloth support results in low equivalent series resistance as seen from Nyquist plots which confirms that it offers low resistance to the diffusion and transport of ions and electrons. The symmetric supercapacitor assembled with the as-prepared PANI/ZnO@ZIF-8-CC electrode and sandwiched $\mathrm{PVA} / \mathrm{KOH}$ electrolyte delivered an areal supercapacitance in the range of $226.9-147.5 \mathrm{mF} / \mathrm{cm}^{2}$ from $0.5-5 \mathrm{~mA} / \mathrm{cm}^{2}$ and cyclic stability of $87 \%$ retention after 10000 cycles.

Apart from oxides, the metal-based chalcogenides and phosphides and MXenes like $\mathrm{WS}_{2}{ }^{[86]} \mathrm{Ni}_{3} \mathrm{~S}_{2}{ }^{[87,88]} \mathrm{Ni}_{3} \mathrm{~S}_{4}{ }^{[89]}$ $\mathrm{MoS}_{2}{ }^{[90,91]} \quad \mathrm{CoS}_{2}{ }^{[92,93]} \quad \mathrm{NiCO}_{2} \mathrm{~S}_{4}{ }^{[94]} \quad \mathrm{NiCO}_{2} \mathrm{O}_{4}{ }^{[32,95]} \quad \mathrm{CoNi}_{2} \mathrm{~S}_{4}{ }^{[96]}$ CoMos, ${ }^{[97]} \mathrm{NiCoP}^{[98]} \mathrm{MOFs}^{[16]}$ and $\mathrm{Ti}_{3} \mathrm{C}_{2} \mathrm{~T}_{x}$ have also been used in carbon cloth-based electrodes. Among these, transition metal dichalcogenides have been the widely investigated electrode materials for super-capacitors and were the promising materials for improving their performances. Most of the transition metal dichalcogenides like $\mathrm{MoS}_{2}$ are layered structures in which the van der Walls forces hold the layer together. $\mathrm{MoS}_{2}$ has graphene-like layered morphology in which the S-Mo-S covalent bonds lie within the basal planes and are held by the weak type of van der Walls forces. Theoretically, $\mathrm{MoS}_{2}$ tends to possess the merit of exhibiting all types of charge storage mechanisms like EDLC behavior due to layered graphene-like structure and pseudo-capacitive nature due to different oxidation states of Mo (from +2 to +6 ) and even cation intercalation between the layers. ${ }^{[99]}$ But the intercalation redox reaction in $\mathrm{MoS}_{2}$ suffers from low kinetics. One way to overcome this problem is to expand the layered $\mathrm{MoS}_{2}$ but it will lead to a decrease in diffusion energy for ion intercalation. ${ }^{[100,101]}$

Sari et al. ${ }^{[91]}$ have coupled $\mathrm{MoS}_{2}$ with $\mathrm{MoO}_{x}$ and the nanostructure was grown upon the activated carbon cloth by the one-step microwave-assisted hydrothermal method. Here, the ACCs played a significant role in enhancing electron transfer, providing good mechanical strength, increasing the electrolyte adsorption. It also acts as a template and provides additional active sites for the growth of vertical $\mathrm{MoS}_{2}$ layer. On the other hand, transition metal phosphides have also gained extensive interest as supercapacitor electrodes due to their large electrical conductivity and good redox activity which was mainly attributed to the low electronegativity of phosphorus which ensures rapid electron transport. ${ }^{[102,103]}$ Self-supported threedimensional core-shell NiCoP@NiCoP on carbon cloth substrate (NiCoP@NiCoP@CC) has been prepared by Zhu et al. ${ }^{[98]}$ via a two-step hydrothermal and a phosphorization method (Figure 6(a)). This leads to the formation of leaf-like arrays directly grown on the carbon cloth support. The as-prepared electrode has integrated advantages of the 1D core which acts as hyperchannel for electron transport, 2D shell for short of diffusion distance for ions and charge carriers which improves cyclic stability. The intimate contact between carbon cloth substrate and active materials provides good mechanical adhesion and electrical connection thereby improving the conductivity which accelerates charge transport resulting in lowering of overall resistance.$^{[104]}$ The asymmetric supercapacitor fabricated by using NiCoP@NiCoP@CC anode and activated carbon cathode delivered high power density outputs of 750 and $7500 \mathrm{~W} / \mathrm{kg}$ at energy densities 34.8 and $18.5 \mathrm{Wh} / \mathrm{kg}$.

\subsection{Growth of Carbon Nanomaterials or their Analogues on Carbon Cloth}

Liu et al. ${ }^{[26]}$ have related the electrochemical performance of the carbon cloths to their surface properties like surface area, porosity, functional groups present in primary carbon fibers from which these are fabricated. In their very recent report, the carbon cloths were functionalized with 3D porous $\mathrm{N}$-doped carbon nanofiber layers which results in the formation of much desirable hierarchical 3D porous electrode for better supercapacitive activity. The resulting electrode delivered a specific capacitance of about $608 \mathrm{mF} / \mathrm{cm}^{2}$ at $1 \mathrm{~mA} / \mathrm{cm}^{2}$ with a good cycle life by retaining almost $99 \%$ capacitance after 5000 cycles. The 3D porous structure can be attributed to playing an important role in better electrochemical performance of electrode. ${ }^{[105]}$ Apart from the porous 3D structure, the doped nitrogen heteroatoms in the electrode offer electrons and this result in the significant change in the electron donor-acceptor characteristics of the carbon materials which cause more increase in their conductivity and surface wettability for accessibility of electrolyte, leading to a better performance compared to the undoped carbon fiber/carbon cloth electrode. ${ }^{[106]}$

Recently, nitrogen and sulfur dual doped carbon cloths have been used as current collectors and polysulfide reservoir in $\mathrm{Mg}-\mathrm{S}$ batteries. ${ }^{[25]}$ It was observed that elemental doping not only improves the ion diffusion in carbon cloths but also reduces the voltage hysteresis loss during charge/discharge. Thus doping can be thought to be more advantageous for improving energy storage in carbon cloths and it was evident from recently reported nitrogen-doped carbon cloths where doping was carried out via simple and facile nitrogen plasma approach. ${ }^{[107]}$ The caused the formation of fine and uniform nanoparticles like structure over carbon microfiber due to high power nitrogen plasma treatment of pristine carbon cloths. The nitrogen heteroatom creates the positive charge centers in carbon materials which make it easy for accepting of electrons and to enhance the resultant electrical conductivity. ${ }^{[108]}$ The CV of as-prepared electrodes shows rectangular-like shape along with redox peaks at anodic and cathodic sites clearly depicting the pseudo-capacitance, mainly due to the presence of nitrogen 
(A)

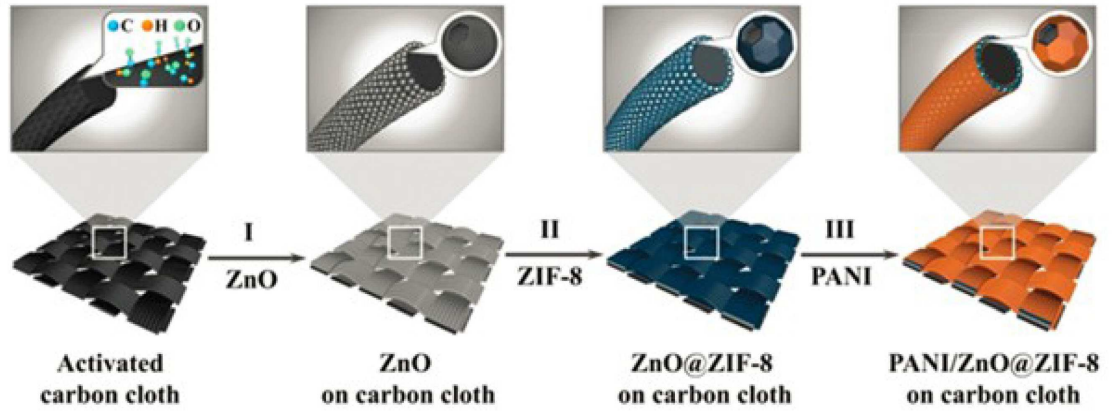

(B)
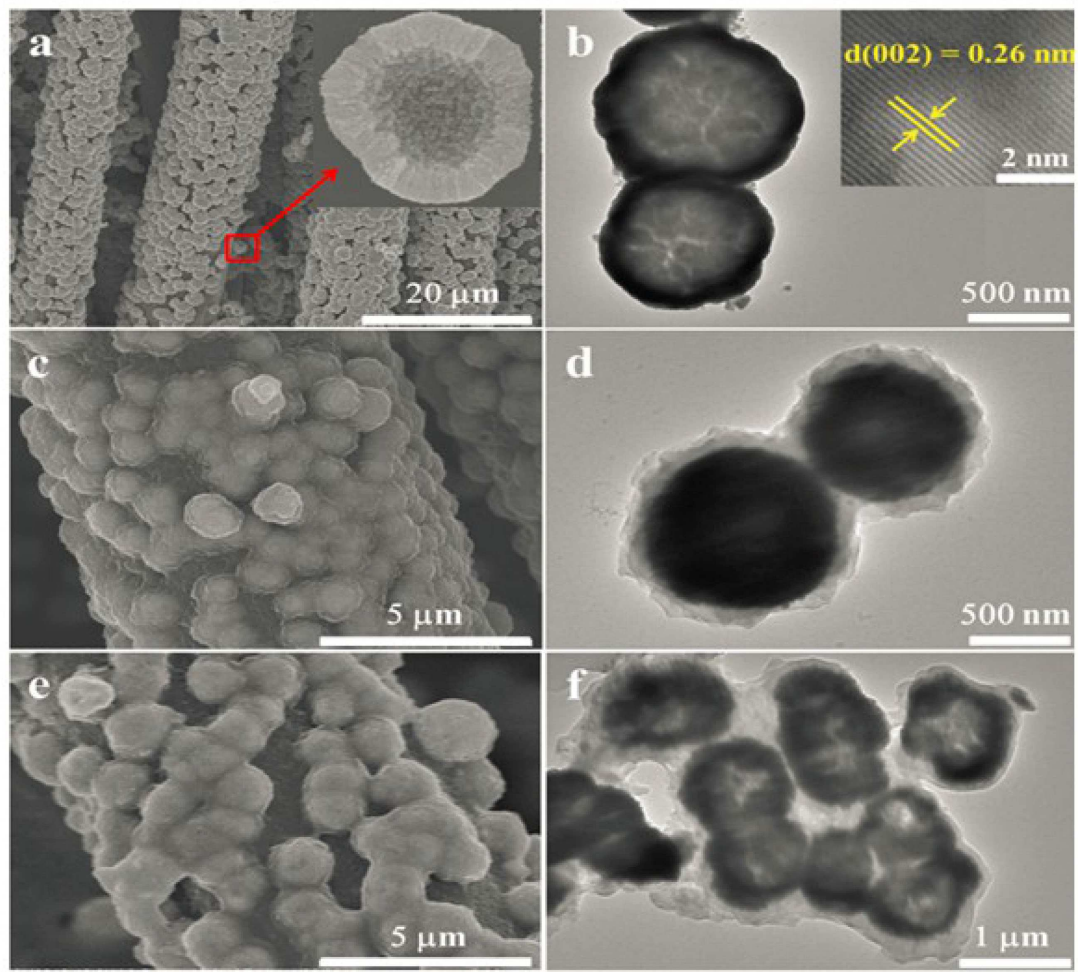

Figure 5. (A) Schematic illustration of PANI/ZnO@ZIF8-CC preparation, (B) SEM (a) and TEM (b) images of ZnO-CC. SEM (c) and TEM images (d) of ZnO@ZIF8CC. SEM (e) and TEM (f) of PANI/ZnO@ZIF8-CC. Reprinted with permission from Ref. [54].

species in carbon cloths and their interaction with the electrolyte.

The pseudo-capacitance behavior is beneficial for enhanced energy storage capacity of the electrode. The CV profile was retained both at lower and higher scanning rates, which shows a better rate capability of the electrode. ${ }^{[109]}$ The as-prepared electrode showed the real capacitance of $741 \mathrm{mF} / \mathrm{cm}^{2}$ at a very low current density of about $0.5 \mathrm{~mA} / \mathrm{cm}^{2}$, which is much higher than the untreated as well as previously reported carbon cloth electrodes. The nanostructures formed over the carbon microfibers also contribute to enhancing the supercapacitor behavior of the electrodes by increasing the electro-active surface area for electrochemical reactions. Thus, the nanostructure growth on carbon fibers would be helpful to enhance the electro- chemical performance. Hu et al. ${ }^{[110]}$ carried out the growth of three-dimensional carbon nano-coils upon the carbon fiber cloth substrates via chemical vapor deposition (Figure 7(a)) by using $\mathrm{Au} / \mathrm{K}$ biocatalyst. The helical structure of the as-formed carbon nano-coils led to the shortening of ion diffusion pathways and results in the formation of more efficient electron transport routes. The growth of the carbon nano-coils contributed to the electroactive surface area or electrochemical active surface area (EASA) was measured by CV technique using the Randles-Sevcik equation [Eq. (1)]:[111]

$$
I_{\mathrm{p}}=2.69 \times 10^{5} \times n^{3 / 2} \times A \times D_{0}^{1 / 2} \times C_{0} \times v^{1 / 2}
$$



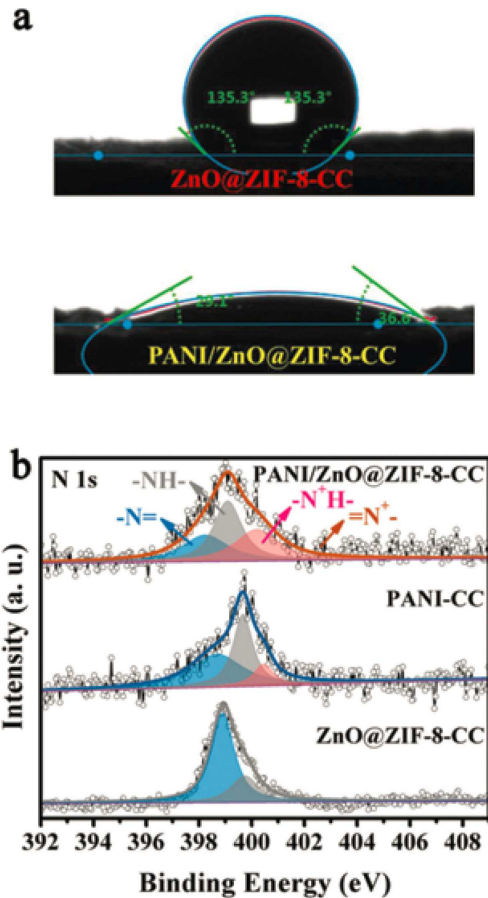
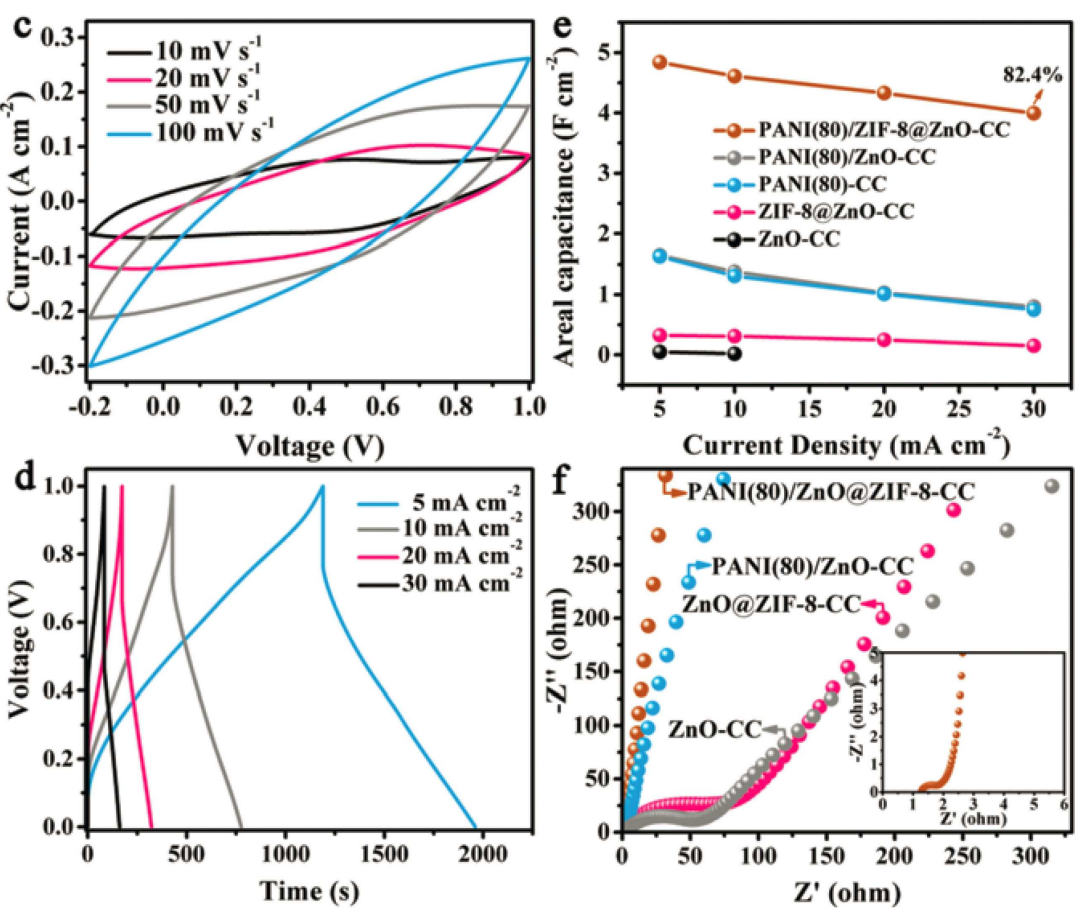

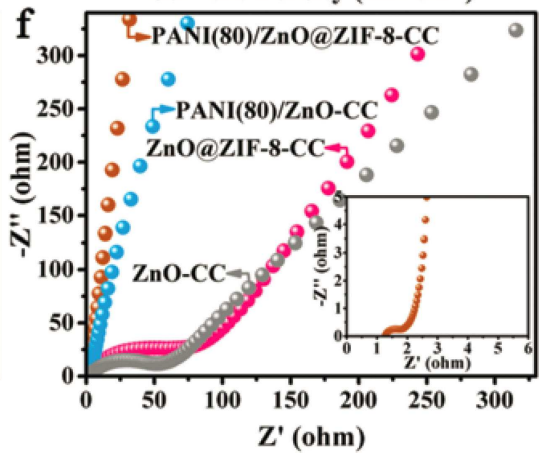

Figure 6. (a) Contact Angle profiles of ZnO@ZIF8-CC and PANI/ZnO@ZIF8-CC, (b) High resolution N1s XPS spectrum of PANI/ZnO@ZIF8-CC, (c) CV and (d) galvanic charge/discharge measurements of PANI/ZnO@ZIF8-CC, (e) Variation of areal capacitances with current and (f) EIS spectra of PANI/ZnO@ZIF8-CC. Reprinted with permission from Ref. [55].

Where $n$ is the number of electrons transferred, $D_{0}$ is a diffusion coefficient, $C_{0}$ is concentration of active species in solution and $v$ is the scan rate. The EASA of carbon nano-coil based electrodes was found to be $16.5 \mathrm{~cm}^{2}$, which was higher than the pristine carbon nano-coil and carbon cloth electrodes. The electrodes were then used to fabricate the solid-state and liquid state symmetric capacitors. The liquid state capacitor composed of a two-electrode system and $1 \mathrm{M} \mathrm{H}_{2} \mathrm{SO}_{4}$ as the electrolyte. The $\mathrm{CV}$ loops (Figure 7(b)) showed rectangular shapes and were unchanged even at higher scan rates up to $80 \mathrm{mV} / \mathrm{s}$, which revealed about rapid charge transfer feature of the device. The symmetric triangular profiles (Figure $7(\mathrm{c})$ ) of galvanostatic charge/discharge in the range $0-1 \mathrm{~V}$ clearly depicts EDLC like charge storage mechanism. ${ }^{[112]}$ The as-prepared electrode was used to fabricate a solid-state symmetric supercapacitor using $\mathrm{H}_{2} \mathrm{SO}_{4}$ /polyvinyl alcohol (PVA) gel as the electrolyte. The CV of the supercapacitor (Figure $7(d)$ ) carried out at different scan rates $(10-100 \mathrm{mV} / \mathrm{s})$ deviate from their rectangular profiles at higher scan rate and also the triangular shape of galvanostatic charge/discharge (Figure 7(e)) get altered at low current densities. This was attributed to longer pathway of ions passing through the surface of electrode to the separator. Also, insufficient covering of the electrode surface with the electrolyte in solid-state capacitor led to increased charge transfer resistance up to 8-times than that of the liquid state capacitor, which may have led to an inefficient charge transfer between the electrolyte gel and the electrode. However, the high leakage resistance of the solid-state capacitor reveals that it is prone to self-discharge than the liquid state device.
As the performance and flexibility in the assembled solidstate super-capacitors depend upon the mechanical and electrical properties of its electrodes, thus there are continuous efforts made to fabricate electrode materials with high capacitance and mechanical strength. The surface oxidation of carbon fibers has recently gained importance to increase their surface area which is desirable for better supercapacitor performance without any significant effect on mechanical strength. It leads to the modification of carbon fiber surface with different oxygen-containing groups.

Wang et al. ${ }^{[18]}$ carried out the surface activation of carbon cloths via chemical exfoliation. The idea was based upon the exfoliation of MWCNTs by Hummer's method. ${ }^{[13]}$ The process was carried out in a solution mixture of strong oxidizing agents like $\mathrm{HNO}_{3}, \mathrm{H}_{2} \mathrm{SO}_{4}$, and $\mathrm{KMnO}_{4}$. Even after oxidation the flexibility and mechanical strength of the carbon cloths are still retained. The smooth surface of carbon fibers in pristine carbon cloths seemed to become rough as observed from SEM and TEM (Figure 8(a)-(d)), which clearly shows the surface modification during the chemical exfoliation process. The modification of carbon fiber surface was also evident from the $\mathrm{N}_{2}$ adsorption/ desorption isotherms and BJH plots (Figure 8(e)), which clearly reveal about the increase in surface area and formation of the mesopores, which is very much required for better supercapacitive activity as evident from the increase in the areas of CV curves (Figure 8(f)). The chemically modified carbon cloths show an increase in the areas of CV curves compared to the pristine carbon cloths revealing about their improved charge storage capacity. 
(a)
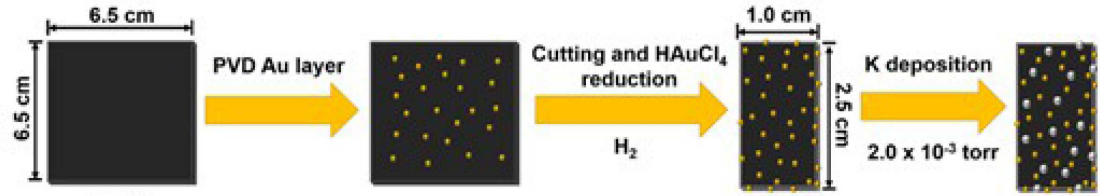

CFC
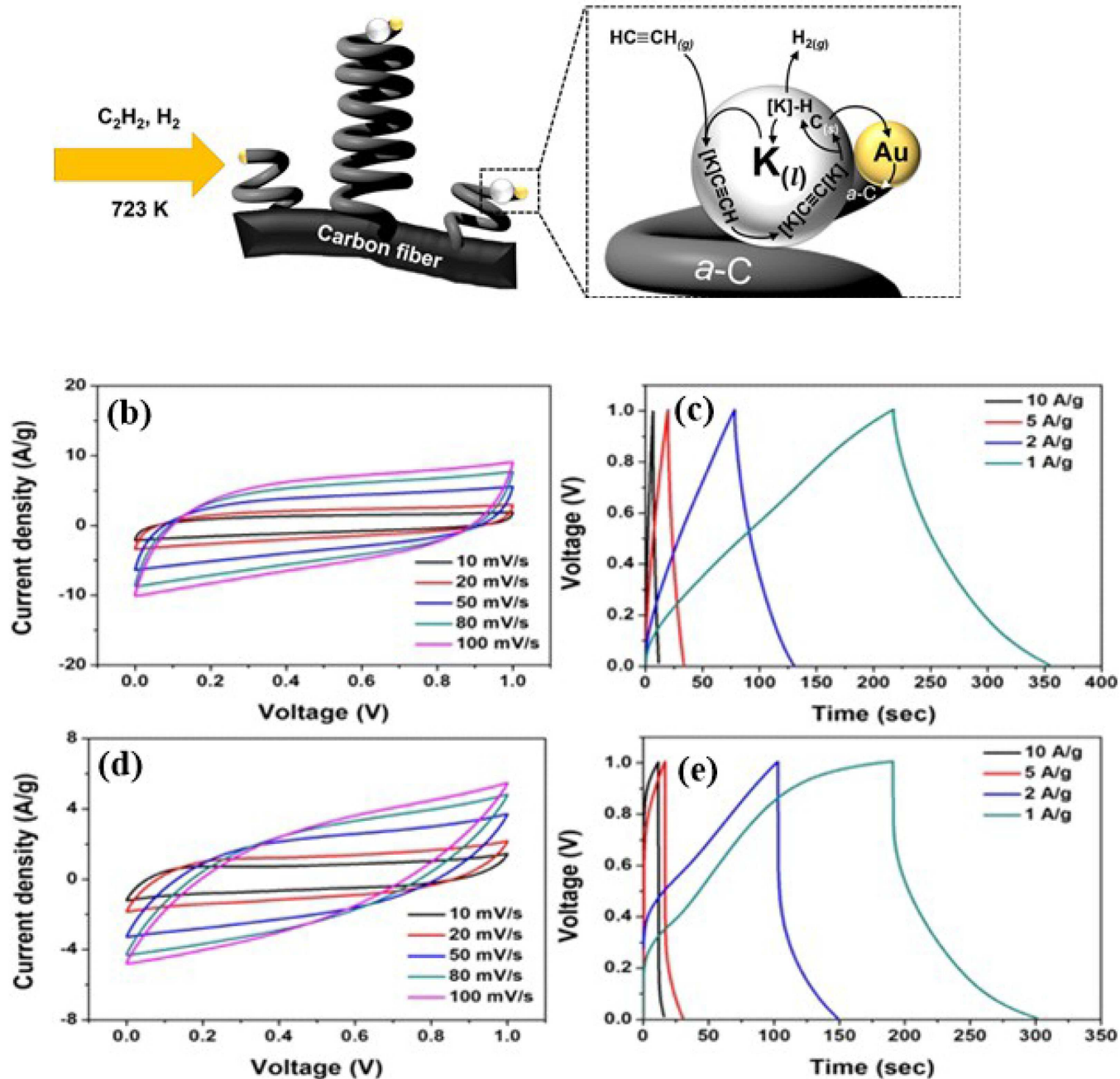

Figure 7. (a) Schematic representation of growth of carbon nanocoil structure on carbon cloths, (b) CV and (c) galvanic charge/discharge measurements of CNC@carbon cloth-based two-electrode liquid state capacitor in $1 \mathrm{M} \mathrm{H}_{2} \mathrm{SO}_{4}$, (d) CV and (e) galvanic charge/discharge measurements of CNC@carbon clothbased two-electrode solid-state capacitor Reprinted with permission from Ref. [116].

The activated carbon cloths modified by two-step reduction process showed better performance than those by single-step reduction. The CV curves of carbon cloths showed the features of a double layer capacitor with their quasi-rectangular shapes and delivered a maximum areal capacitance of $88 \mathrm{mF} / \mathrm{cm}^{2}$ at a scan rate of $10 \mathrm{mV} / \mathrm{s}$. The obtained capacitance was 140 times higher than that of untreated carbon cloths under the same conditions. The increased surface area and formation of pores significantly contributed to the superior electrochemical supercapacitance. Solid-state super-capacitor (Figure 8(g)) fabricated from the chemically treated carbon cloths exhibited rectangular CVs (Figure $8(\mathrm{~h})-(\mathrm{i})$ ) even at a high scan rate of $10000 \mathrm{mV} / \mathrm{s}$ revealing the excellent double-layer capacitive behavior with a maximum areal capacitance of $31 \mathrm{mF} / \mathrm{cm}^{2}$ at a scan rate of
$10 \mathrm{mV} / \mathrm{s}$ with retention of $73 \%$ of initial capacitance between $10-10000 \mathrm{mV} / \mathrm{s}$.

Du et al. ${ }^{[14]}$ modified the surface of functionalized carbon cloths with vertically aligned graphene wrapped PANI nanorods arrays. The functionalization was carried out by treating the carbon cloth in a 2:1 mixture of $\mathrm{H}_{2} \mathrm{SO}_{4} / \mathrm{HNO}_{3}$ and $\mathrm{KMnO}_{4}$ after which their surface was incorporated with $\mathrm{rGO}$ wrapped PANI nanorods arrays. The functionalization has led to the oxidation of carbon cloth surface, leading to an increase in its hydrophilicity. The wrapping with $\mathrm{rGO}$ was done to provide mechanical strength since PANI nanorods without rGO incorporation were more prone to shrinking and swelling which can affect long term cycling stability of the electrode. ${ }^{[115,116]}$ The rGO increased electrical conductivity and plays an important role in 

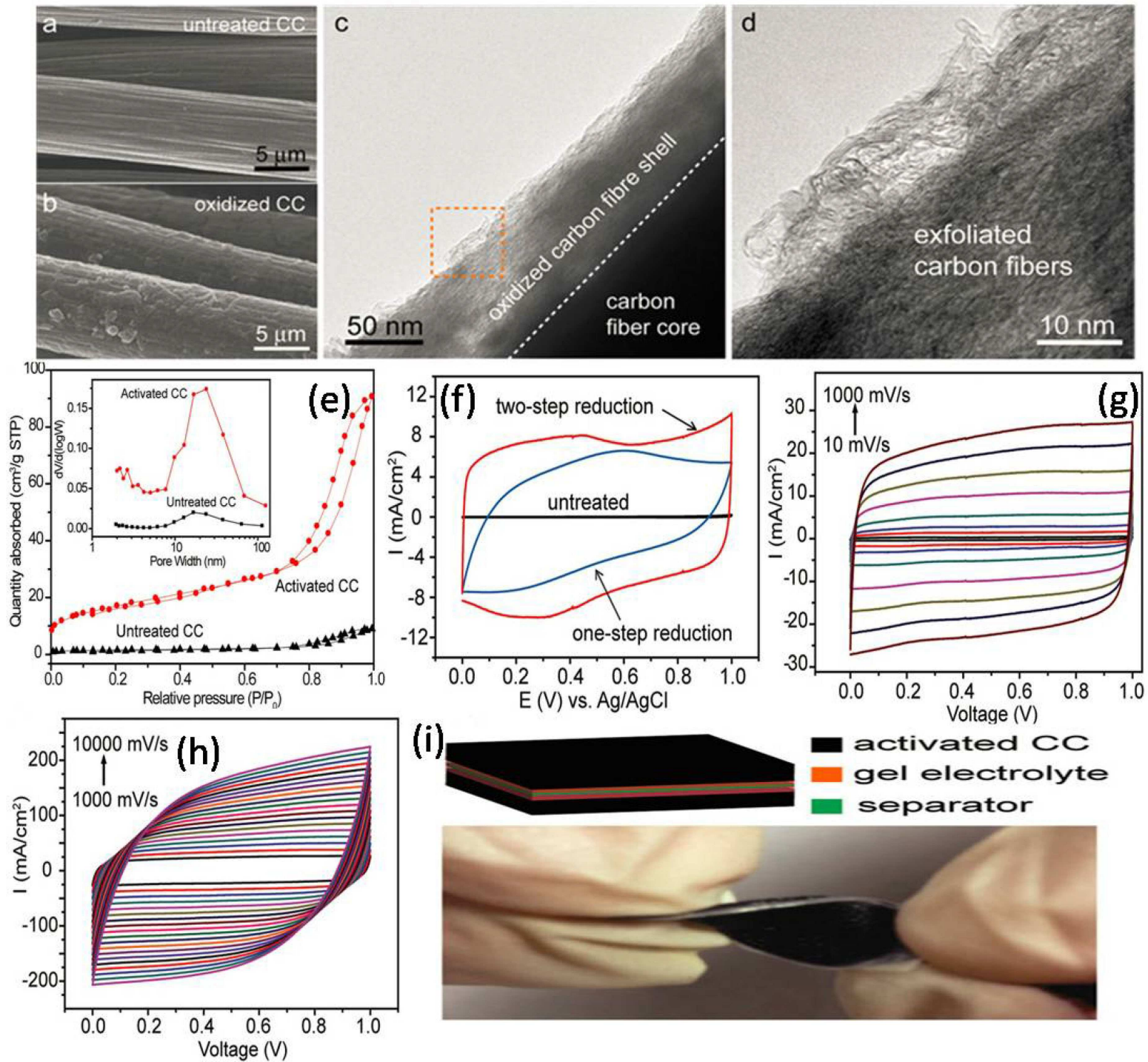

Figure 8. SEM (a-b) and TEM (c-d) images of pristine and chemically exfoliated carbon cloths, (e) $\mathrm{N}_{2}$ adsorption/desorption isotherm, (f) CV of pristine and chemically exfoliated carbon cloths, (g) and (h) CV of solid-state supercapacitor derived from chemically exfoliated carbon cloths under different scan rates, (i) architectural view of solid-state supercapacitor derived from chemically exfoliated carbon cloths Reprinted with permission from Ref. [31].

enhancing the capacitance. ${ }^{[117,118]}$ However, incorporation of rGO restricts charge transfer channels at a high current density which decreases the rate capability of the electrode. ${ }^{[117]}$ Asymmetric solid-state and flexible supercapacitor was fabricated out of the as-prepared electrode using $\mathrm{H}_{2} \mathrm{SO}_{4} /$ PVA solid gel electrolyte and showed pseudo-capacitive behavior due to the presence of PANI. It also showed unchanged performance upon bending it from 0 to $180^{\circ} \mathrm{C}$ depicting excellent mechanical strength and flexibility.

In a recent attempt, Zheng et al. ${ }^{[119]}$ prepared the nitrogendoped carbon fiber cloth in which carbon fibers were functionalized with oxygen-containing groups. For this purpose, the pre-oxidized polyacrylonitrile cloth was annealed and it was further oxidized in a mixture of concentrated $\mathrm{H}_{2} \mathrm{SO}_{4}$ and $\mathrm{HNO}_{3}$. In the process, the content of doped nitrogen can be controlled by varying the annealing temperature. The treatment with concentrated acids facilitated the etching at room temperature and it leads to the introduction of oxygen-based functional groups like $>\mathrm{C}-\mathrm{OH}$ and $-\mathrm{COOH}$. The oxygen-containing functional groups impart better wettability or the hydrophilicity to the carbon cloth electrode, which is essential for its better interfacial contact with the electrolyte. The as-prepared material delivered an areal and gravimetric specific capacitance of about $1385 \mathrm{mF} / \mathrm{cm}^{2}$ and $294.7 \mathrm{~F} / \mathrm{g}$ at the current density of $1 \mathrm{~mA} / \mathrm{cm}^{2}$. Also, it had lower charge transfer resistance, which implied better diffusion of ions from the interior of the carbon cloth to the electrolyte due to larger electrode/electrolyte interface. It retained $65 \%$ of initial capacitance even at a high current density of $30 \mathrm{~mA} / \mathrm{cm}^{2}$ showing exceptional stability. On the other hand, it showed excellent cycling stability by retaining almost $99 \%$ capacitance after 10000 cycles. The as-fabricated supercapacitor provided specific area and gravimetric capacitances of $569.6 \mathrm{mF} / \mathrm{cm}^{2}$ and $116.2 \mathrm{~F} / \mathrm{g}$ at a current density of $0.1 \mathrm{~mA} / \mathrm{cm}^{2}$ which was retained up to $98.8 \%$ of the initial value 
after 5000 cycles at a current density of $0.2 \mathrm{~mA} / \mathrm{cm}^{2}$. The device exhibited the energy and power density of about $19.8 \mu \mathrm{Wh} / \mathrm{cm}^{2}$ $(4.03 \mathrm{Wh} / \mathrm{kg})$ and $50.1 \mu \mathrm{W} / \mathrm{cm}^{2}(10.2 \mathrm{~W} / \mathrm{kg})$, which was superior to that of the device fabricated from porous graphene@carbon cloth electrode which delivered power density of $1.63 \mathrm{~W} / \mathrm{kg}^{[120]}$ Thus the introduction of wettability or hydrophilicity in carbon cloths can be of great help in performance enhancement as it promotes better transportation of ions at the electrode/electrolyte interface. ${ }^{[120]}$

\section{Conclusions and Outlook}

Carbon cloths are very promising materials for super-capacitor electrode fabrication due to their eco-friendly nature, biocompatibility, low toxicity, high mechanical strength, and high electrical conductivity. They can be obtained from the naturally occurring materials like jute fibers and silk by a facile carbonization process. However, their low surface area and porosity are some of the demerits, which make the pristine carbon cloth unsuitable as a super-capacitor electrode. Some strategies have been developed to make them useful to work as supercapacitor electrodes. One such approach is the modification of carbon cloth surface by oxidation under acidic medium containing 2:1 mixture of $\mathrm{H}_{2} \mathrm{SO}_{4}$ and $\mathrm{HNO}_{3}$ and $\mathrm{KMnO}_{4}$, which is also called activation of carbon cloths. The activation of carbon cloths results in inducing of oxygen-containing functional groups over the carbon fibers. It also leads to an increase in surface area and porosity, which is necessary for their applications in the fields of catalysis and supercapacitors. Apart from this, more stress should be laid upon the use of carbonrich resources like waste plastic and biomass for the fabrication of carbon cloths with improved surface properties and flexibility. Also, emphasis should be laid for the development of chemical processes meant for the synthesis of carbon cloths and their enrichment, which can make them more effective towards energy storage applications. This may lead to an effective cost reduction in the fabrication of wearable supercapacitors as these are easily available. On the other hand, carbon cloth-based hybrids can be of great help in the fabrication of devices having both super-capacitive and pseudo-capacitive behavior with improved energy storage.

Carbon cloths are also coupled to pseudo-capacitive materials like metal oxides and conducting polymers and supercapacitor materials like MXenes were also incorporated on carbon cloths, which would further increase their supercapacitive performance by enhancing the charge transfer and ion diffusion processes, leading to increase in specific capacitance. The electrodes derived from carbon cloths were used to fabricate both symmetric and asymmetric supercapacitor devices with high energy and power densities. Also, carbon cloth imparts high mechanical strength and flexibility, which makes them promising for their use in all solid-state supercapacitors. The super-capacitors derived from carbon cloths possess high flexibility as the electrochemical behavior analyzed from CV was found to be intact even after bending the device up to 180 degrees in many of the reports. Thus, certainly there will be brighter prospects for these materials in the smooth running of wearable and portable electronic devices such as motion sensors, skin patchable health monitoring devices, wearable watches, etc.

\section{Conflict of Interest}

The authors declare no conflict of interest.

Keywords: nanostructured carbons - carbon cloth - flexible electrodes $\cdot$ energy storage $\cdot$ lectrochemical supercapacitors

[1] S. Chu, A. Majumdar, Nature 2012, 488, 294-303.

[2] V. N. Rao, N. L. Reddy, N. M. Kumari, P. Ravi, M. Satish, K. M. Kuruvilla, V. Preethi, K. R. Reddy, N. P. Shetti, T. M. Aminabhavi, M. V. Shankar, Appl. Catal. B 2019, 254, 174-185.

[3] M. H. Sahir, A. H. Qureshi, Renewable Sustainable Energy Rev. 2008, 12, 290-298.

[4] J. Duan, Q. Tang, Dalton Trans. 2019, 48, 799-805.

[5] M. Cakici, K. R. Reddy, F. Alonso-Marroquin, Chem. Eng. J. 2017, 309, $151-158$.

[6] C. V. Reddy, I. N. Reddy, K. R. Reddy, S. Jaesool, K. Yoo, Electrochim. Acta 2019, 317, 416-426.

[7] V. Aravindan, S. Jayaraman, F. Tedjar, S. Madhavi, ChemElectroChem 2019, 6, 1407-1412.

[8] J. Zhao, C. Li, Q. Zhang, J. Zhang, X. Wang, Z. Lin, J. Wang, W. Lv, C. Lu, C.-p. Wong, J. Mater. Chem. A 2017, 5, 6928-6936.

[9] A. Mishra, A. Mehta, S. Basu, S. J. Malode, N. P. Shetti, S. S. Shukla, M. N. Nadagouda, T. M. Aminabhavi, Mater. Sci. Energy Technol. 2018, 1, 182187.

[10] N. P. Shetti, S. Dias, K. R. Reddy, Mater. Sci. Semicond. Process. 2019, 104, 104684.

[11] J. Zhao, C. Li, Q. Zhang, J. Zhang, X. Wang, J. Sun, J. Wang, J. Xie, C. Lu, W. Lu, Carbon 2017, 123, 676-682.

[12] M. Hassan, E. Haque, K. R. Reddy, A. I. Minett, J. Chen, V. G. Gomes, Nanoscale 2014, 6, 11988-11994.

[13] J. Zhao, L. Li, Y. Zhang, C. Li, Q. Zhang, J. Peng, X. Zhao, Q. Li, X. Wang, J. Xie, Energy Storage Mater. 2018, 15, 315-323.

[14] Y. Ouyang, H. Ye, X. Xia, X. Jiao, G. Li, S. Mutahir, L. Wang, D. Mandler, W. Lei, Q. Hao, J. Mater. Chem. A 2019, 7, 3228-3237.

[15] H. Zhou, X. Li, Y. Li, M. Zheng, H. Pang, Nano-Micro Lett. 2019, 11, 40.

[16] Z. Tang, G. Zhang, H. Zhang, L. Wang, H. Shi, D. Wei, H. Duan, Energy Storage Mater. 2018, 10, 75-84.

[17] J. Ma, J. Li, R. Guo, H. Xu, F. Shi, F. Dang, X. Liu, J. Sun, Z. Lei, J. Power Sources 2019, 428, 124-130.

[18] J. Wu, W.-W. Liu, Y.-X. Wu, T.-C. Wei, D. Geng, J. Mei, H. Liu, W.-M. Lau, L.-M. Liu, Electrochim. Acta 2016, 203, 21-29.

[19] A. Perrard, P. Gallezot, J.-P. Joly, R. Durand, C. Baljou, B. Coq, P. Trens, Appl. Catal. A 2007, 331, 100-104.

[20] Y. Shen, X. Ren, X. Qi, J. Zhou, G. Xu, Z. Huang, J. Zhong, J. Mater. Sci. 2017, 28, 768-772.

[21] C. Nieto-Delgado, D. Partida-Gutierrez, J. R. Rangel-Mendez, J. Cleaner Prod. 2019, 213 650-658.

[22] Y. Li, C. Cheng, S. Bai, L. Jing, Z. Zhao, L. Liu, Chem. Eng. J. 2019, 365 317-324.

[23] E. Dimotakis, M. Cal, J. Economy, M. Rood, S. Larson, Environ. Sci. Technol. 1995, 29, 1876-1880.

[24] L. Huang, Y. Zhang, C. Shang, X. Wang, G. Zhou, J. Z. Ou, Y. Wang, ChemElectroChem 2019, 6, 461-466.

[25] D. Muthuraj, A. Ghosh, A. Kumar, S. Mitra, ChemElectroChem 2019, 6, 684-689.

[26] Y.-N. Liu, J.-N. Zhang, H.-T. Wang, X.-H. Kang, S.-W. Bian, Mater. Chem. Front. 2019, 3, 25-31.

[27] W. Lu, R. Jiang, X. Yin, L. Wang, Nano Res. 2019, 12, 159-163.

[28] X. Wei, Y. Li, H. Peng, M. Zhou, Y. Ou, Y. Yang, Y. Zhang, P. Xiao, Chem. Eng. J. 2018, 341, 618-627.

[29] G. Li, R. Li, W. Zhou, Nano-Micro Lett. 2017, 9, 46. 
[30] X. Wei, W. Hu, H. Peng, Y. Xiong, P. Xiao, Y. Zhang, G. Cao, Small 2019, 15,1902280

[31] J. Xue, L. Gao, X. Hu, K. Cao, W. Zhou, W. Wang, Y. Lu, Nano-Micro Lett. $2019,11,46$

[32] Y. Ouyang, R. Huang, X. Xia, H. Ye, X. Jiao, L. Wang, W. Lei, Q. Hao, Chem. Eng. J. 2019, 355, 416-427.

[33] G. Ma, Z. Zhang, K. Sun, E. Feng, H. Peng, X. Zhou, Z. Lei, J. Power Sources 2019, 330, 219-230.

[34] J. Menzel, E. Frackowiak, K. Fic, J. Power Sources 2019, 414, 183-191.

[35] Y. Lin, H. Zhang, W. Deng, D. Zhang, N. Li, Q. Wu, C. He, J. Power Sources 2018, 384, 278-286.

[36] M. Yu, Y. Zeng, Y. Han, X. Cheng, W. Zhao, C. Liang, Y. Tong, H. Tang, X. Lu, Adv. Funct. Mater. 2015, 25, 3534-3540.

[37] H. Ji, X. Liu, Z. Liu, B. Yan, L. Chen, Y. Xie, C. Liu, W. Hou, G. Yang, Adv. Funct. Mater. 2015, 25, 1886-1894.

[38] S. He, W. Chen, J. Power Sources 2015, 294, 150-158.

[39] X. Zhang, P. Yu, H. Zhang, D. Zhang, X. Sun, Y. Ma, Electrochim. Acto 2013, 89, 523-529.

[40] L. Peng, X. Peng, B. Liu, C. Wu, Y. Xie, G. Yu, Nano Lett. 2013, 13, $2151-$ 2157.

[41] X. Fan, X. Wang, G. Li, A. Yu, Z. Chen, J. Power Sources 2016, 326, $357-$ 364.

[42] L. Feng, G. Li, S. Zhang, Y. X. Zhang, Ceram. Int. 2017, 43, 8321-8328.

[43] I. E. Rauda, V. Augustyn, L. C. Saldarriaga-Lopez, X. Chen, L. T. Schelhas, G. W. Rubloff, B. Dunn, S. H. Tolbert, Adv. Funct. Mater. 2014, 24, 67176728.

[44] X. Zhou, Q. Chen, A. Wang, J. Xu, S. Wu, J. Shen, ACS Appl. Mater. Interfaces 2016, 8, 3776-3783.

[45] J. Tao, N. Liu, W. Ma, L. Ding, L. Li, J. Su, Y. Gao, Sci. Rep. 2013, 3, 2286

[46] W. Zhou, J. Xu, Polymer Rev. 2017, 57, 248-275.

[47] C. X. Guo, G. Yilmaz, S. Chen, S. Chen, X. Lu, Nano Energy 2015, 12, 76 87.

[48] F. Li, J. Chen, X. Wang, M. Xue, G. Chen, Adv. Funct. Mater. 2015, 25 , $4601-4606$.

[49] X. Chen, K. Chen, H. Wang, D. Xue, Composition design upon iron element toward supercapacitor electrode materials, Mater. Focus 2015, $4,78-80$.

[50] Z. Zhang, H. Wang, Y. Zhang, X. Mu, B. Huang, J. Du, J. Zhou, X. Pan, E. Xie, Chem. Eng. J. 2017, 325, 221-228.

[51] D. Chen, S. Zhou, H. Quan, R. Zou, W. Gao, X. Luo, L. Guo, Chem. Eng. J. 2018, 341, 102-111.

[52] J. Li, Y. Wang, W. Xu, Y. Wang, B. Zhang, S. Luo, X. Zhou, C. Zhang, X. Gu, C. Hu, Nano Energy 2019, 57, 379-387.

[53] P. Lian, Y. Dong, Z.-S. Wu, S. Zheng, X. Wang, S. Wang, C. Sun, J. Qin, X. Shi, X. Bao, Nano Energy 2017, 40, 1-8.

[54] C. Zhang, B. Anasori, A. Seral-Ascaso, S. H. Park, N. McEvoy, A. Shmeliov, G. S. Duesberg, J. N. Coleman, Y. Gogotsi, V. Nicolosi, Adv. Mater. 2017, 29, 1702678.

[55] Y. Dong, Z.-S. Wu, S. Zheng, X. Wang, J. Qin, S. Wang, X. Shi, X. Bao, ACS Nano 2017, 11, 4792-4800.

[56] J. Luo, W. Zhang, H. Yuan, C. Jin, L. Zhang, H. Huang, C. Liang, Y. Xia, J. Zhang, Y. Gan, ACS Nano 2017, 11, 2459-2469.

[57] M. Hu, T. Hu, R. Cheng, J. Yang, C. Cui, C. Zhang, X. Wang, J. Energy Chem. 2018, 27, 161-166.

[58] M. Naguib, M. Kurtoglu, V. Presser, J. Lu, J. Niu, M. Heon, L. Hultman, Y. Gogotsi, M. W. Barsoum, Adv. Mater. 2011, 23, 4248-4253.

[59] J. L. Hart, K. Hantanasirisakul, A. C. Lang, B. Anasori, D. Pinto, Y. Pivak, J. T. van Omme, S. J. May, Y. Gogotsi, M. L. Taheri, Nat. Commun. 2019, $10,522$.

[60] T. Hu, H. Zhang, J. Wang, Z. Li, M. Hu, J. Tan, P. Hou, F. Li, X. Wang, Sci. Rep. 2015, 5, 16329.

[61] N. Kurra, B. Ahmed, Y. Gogotsi, H. N. Alshareef, Adv. Energy Mater. 2016, 6, 1601372

[62] K. R. Reddy, C. V. Reddy, M. N. Nadagouda, N. P. Shetti, S. Jaesool, T. M. Aminabhavi, J. Environmental Management 2019, 238, 25-40.

[63] M. Hu, Z. Li, H. Zhang, T. Hu, C. Zhang, Z. Wu, X. Wang, Chem. Commun. 2015, 51, 13531-13533.

[64] A. Rising, H. Nimmervoll, S. Grip, A. Fernandez-Arias, E. Storckenfeldt D. P. Knight, F. Vollrath, W. Engström, Zool. Sci. 2005, 22, 273-282.

[65] P. A. Shinde, V. C. Lokhande, T. Ji, C. D. Lokhande, J. Colloid Interface Sci. 2017, 498, 202-209.

[66] Z. Chen, L. Zheng, T. Zhu, Z. Ma, Y. Yang, C. Wei, L. Liu, X. Gong, Adv. Electron. Mater. 2019, 5, 1800721.

[67] J. Ling, H. Zou, W. Yang, W. Chen, K. Lei, S. Chen, J. Energy Storage 2018, 20, 92-100.
[68] I. Aldama, V. Barranco, T. Centeno, J. Ibañez, J. Rojo, J. Electrochem. Soc. 2016, 163, A758-A765.

[69] Y. Ouyang, X. Xia, H. Ye, L. Wang, X. Jiao, W. Lei, Q. Hao, ACS Appl. Mater. Interfaces 2018, 10, 3549-3561.

[70] S. Razali, S. Majid, Mater. Des. 2018, 153, 24-35.

[71] K. Lu, B. Song, K. Li, J. Zhang, H. Ma, J. Power Sources 2017, 370, 98105.

[72] D. Murugesan, S. Prakash, N. Ponpandian, P. Manisankar, C. Viswanathan, Colloids Surf. A 2019, 569, 137-144.

[73] X.-M. Cao, Z.-B. Han, Chem. Commun. 2019, 55, 1746-1749.

[74] C. Zhu, Y. He, Y. Liu, N. Kazantseva, P. Sáha, Q. Cheng, J. Energy Chem. 2019, 35, 124-131.

[75] S.-H. Ji, N. R. Chodankar, W.-S. Jang, D.-H. Kim, Electrochim. Acta 2019, $299,245-252$

[76] C. Guan, X. Qian, X. Wang, Y. Cao, Q. Zhang, A. Li, J. Wang, Nanotechnology 2015, 26, 094001.

[77] Y. Zhao, X. He, R. Chen, Q. Liu, J. Liu, J. Yu, J. Li, H. Zhang, H. Dong, M. Zhang, Chem. Eng. J. 2018, 352, 29-38.

[78] L. Huang, W. Zhang, J. Xiang, H. Xu, G. Li, Y. Huang, Sci. Rep. 2016, 6, 31465.

[79] Z. Deng, J. Luo, L. Yang, J. Liu, K. Zhu, J. Min, G. Wang, J. Sol-Gel Sci. Technol. 2019, 89, 486-491.

[80] X. He, Y. Zhao, R. Chen, H. Zhang, J. Liu, Q. Liu, D. Song, R. Li, J. Wang, ACS Sustainable Chem. Eng. 2018, 6, 14945-14954.

[81] C. V. Reddy, K. R. Reddy, V. V. N. Harish, J. Shim, M. V. Shankar, N. P. Shetti, T.M. Aminabhavi, International Journal of Hydrogen Energy 2019, https://doi.org/10.1016/j.jijydene.2019.02.144.

[82] Y. Zhang, Y. Wang, L. Liu, N. Wei, M.-L. Gao, D. Zhao, Z.-B. Han, Inorg. Chem. 2018, 57, 2193-2198.

[83] N. Wei, R.-X. Zuo, Y.-Y. Zhang, Z.-B. Han, X.-J. Gu, Chem. Commun. 2017, 53, 3224-3227.

[84] M. Kim, C. Lee, J. Jang, Adv. Funct. Mater. 2014, 24, 2489-2499.

[85] K. Zhou, Y. He, Q. Xu, Q. E. Zhang, A. A. Zhou, Z. Lu, L.-K. Yang, Y. Jiang, D. Ge, X. Y. Liu, ACS Nano 2018, 12, 5888-5894.

[86] X. Shang, J.-Q. Chi, S.-S. Lu, J.-X. Gou, B. Dong, X. Li, Y.-R. Liu, K.-L. Yan, Y.-M. Chai, C.-G. Liu, Appl. Surf. Sci. 2017, 392, 708-714.

[87] Z. Tian, J. Yin, X. Wang, Y. Wang, J. Alloys Compd. 2019, 777, 806-811.

[88] P. Dhaiveegan, Y.-K. Hsu, Y.-H. Tsai, C.-K. Hsieh, J.-Y. Lin, Surf. Coat. Technol. 2018, 350, 1003-1009.

[89] F. Huang, Y. Sui, F. Wei, J. Qi, Q. Meng, Y. He, J. Mater. Sci. 2018, 29, $2525-2536$

[90] S. Li, T. Chen, J. Wen, P. Gui, G. Fang, Nanotechnology 2017, 28, 445407.

[91] F. N. I. Sari, J. M. Ting, ChemSusChem 2018, 11, 897-906.

[92] C. Su, J. Xiang, F. Wen, L. Song, C. Mu, D. Xu, C. Hao, Z. Liu, Electrochim. Acta 2016, 212, 941-949.

[93] M. Govindasamy, S. Shanthi, E. Elaiyappillai, S.-F. Wang, P. M. Johnson, H. Ikeda, Y. Hayakawa, S. Ponnusamy, C. Muthamizhchelvan, Electrochim. Acta 2019, 293, 328-337.

[94] X. Xu, X. Tian, X. Li, T. Yang, Y. He, K. Wang, Y. Song, Z. Liu, Appl. Surf. Sci. 2019, 465, 635-642.

[95] Y. Jiang, L. Zhang, H. Zhang, C. Zhang, S. Liu, J. Power Sources 2016 , $329,473-483$

[96] C. Su, S. Xu, L. Zhang, X. Chen, G. Guan, N. Hu, Y. Su, Z. Zhou, H. Wei, Z. Yang, Electrochim. Acta 2019, 305, 81-89.

[97] S. J. Patil, D.-W. Lee, J. Mater. Chem. A 2018, 6, 9592-9603.

[98] Y. Zhu, Q. Zong, Q. Zhang, H. Yang, Q. Wang, H. Wang, Electrochim. Acta 2019, 299, 441-450.

[99] J. M. Soon, K. P. Loh, Electrochem. Solid-State Lett. 2017, 10, A250A254.

[100] K. D. Rasamani, F. Alimohammadi, Y. Sun, Mater. Today 2017, 20, 8391.

[101] J. Chen, Y. Xia, J. Yang, Mater. Lett. 2018, 210, 248-251.

[102] Y. Lan, H. Zhao, Y. Zong, X. Li, Y. Sun, J. Feng, Y. Wang, X. Zheng, Y. Du, Nanoscale 2018, 10, 11775-11781.

[103] Y. Shao, Y. Zhao, H. Li, C. Xu, ACS Appl. Mater. Interfaces 2016, 8, 35368-35376.

[104] X. Li, H. Wu, A. M. Elshahawy, L. Wang, S. J. Pennycook, C. Guan, J. Wang, Adv. Funct. Mater. 2018, 28, 1800036.

[105] J. Wu, P. Guo, R. Mi, X. Liu, H. Zhang, J. Mei, H. Liu, W.-M. Lau, L.-M. Liu, J. Mater. Chem. A 2015, 3, 15331-15338.

[106] X. Yu, J. Zhao, R. Lv, Q. Liang, C. Zhan, Y. Bai, Z.-H. Huang, W. Shen, F. Kang, J. Mater. Chem. A 2015, 3, 18400-18405.

[107] N. R. Chodankar, S.-H. Ji, D.-H. Kim, J. Electrochem. Soc. 2018, 165, A2446-A2450. 
[108] J. Zhao, H. Lai, Z. Lyu, Y. Jiang, K. Xie, X. Wang, Q. Wu, L. Yang, Z. Jin, Y. Ma, Adv. Mater. 2015, 27, 3541-3545.

[109] X. Huang, M. Kim, H. Suh, I. Kim, Korean J. Chem. Eng. 2016, 33, 22282234.

[110] S. Hu, C.-Y. Lee, H.-T. Chiu, ACS Omega 2019, 4, 195-202.

[111] A. J. Bard, L. R. Faulkner, Fundamentals and applications, Electrochem. Methods 2001, 2, 482.

[112] H.-Q. Wang, Z.-S. Li, Y.-G. Huang, Q.-Y. Li, X.-Y. Wang, J. Mater. Chem. 2010, 20, 3883-3889.

[113] G. Wang, Y. Ling, F. Qian, X. Yang, X.-X. Liu, Y. Li, J. Power Sources 2011, $196,5209-5214$

[114] P. Du, Y. Dong, H. Kang, X. Yang, Q. Wang, J. Niu, S. Wang, P. Liu, ACS Sustainable Chem. Eng. 2018, 6, 14723-14733.
[115] J. Deng, T. Wang, J. Guo, P. Liu, Prog. Nat. Sci. 2017, 27, 257-260.

[116] J. Wang, J. Wu, H. Bai, Energy Environ. Sci. 2017, 10, 2372-2382.

[117] Q. Hao, X. Xia, W. Lei, W. Wang, J. Qiu, Carbon 2015, 81, 552-563.

[118] W. Fan, C. Zhang, W. W. Tjiu, K. P. Pramoda, C. He, T. Liu, ACS Appl. Mater. Interfaces 2013, 5, 3382-3391.

[119] Y. Zheng, W. Zhao, D. Jia, L. Cui, J. Liu, Chem. Eng. J. 2019, 364, 70-78.

[120] S. Wang, B. Pei, X. Zhao, R. A. Dryfe, Nano Energy 2013, 2, 530-536.

Manuscript received: July 7, 2019

Revised manuscript received: September 15, 2019

Accepted manuscript online: September 22, 2019 